\title{
Radiopharmaceutical and $\mathrm{Eu}^{3+}$ doped gadolinium oxide nanoparticles mediated triple-excited fluorescence imaging and image-guided surgery
}

Xiaojing Shi ${ }^{1,2}$, Caiguang Cao ${ }^{1,2}$, Zeyu Zhang ${ }^{1,3}$, Jie Tian ${ }^{1,2,3^{*}}$ (ID and Zhenhua Hu 1,2* $^{*^{*}}$

\begin{abstract}
Cerenkov luminescence imaging (CLI) is a novel optical imaging technique that has been applied in clinic using various radionuclides and radiopharmaceuticals. However, clinical application of CLI has been limited by weak optical signal and restricted tissue penetration depth. Various fluorescent probes have been combined with radiopharmaceuticals for improved imaging performances. However, as most of these probes only interact with Cerenkov luminescence $(\mathrm{CL})$, the low photon fluence of $\mathrm{CL}$ greatly restricted it's interaction with fluorescent probes for in vivo imaging. Therefore, it is important to develop probes that can effectively convert energy beyond $C L$ such as $\beta$ and $\gamma$ to the low energy optical signals. In this study, a Eu ${ }^{3+}$ doped gadolinium oxide $\left(\mathrm{Gd}_{2} \mathrm{O}_{3}\right.$ :Eu) was synthesized and combined with radiopharmaceuticals to achieve a red-shifted optical spectrum with less tissue scattering and enhanced optical signal intensity in this study. The interaction between $\mathrm{Gd}_{2} \mathrm{O}_{3}$ :Eu and radiopharmaceutical were investigated using ${ }^{18} \mathrm{~F}$-fluorodeoxyglucose $\left({ }^{18} \mathrm{~F}-\mathrm{FDG}\right)$. The ex vivo optical signal intensity of the mixture of $\mathrm{Gd}_{2} \mathrm{O}_{3}$ :Eu and ${ }^{18} \mathrm{~F}$-FDG reached 369 times as high as that of $\mathrm{CLI}$ using ${ }^{18} \mathrm{~F}-\mathrm{FDG}$ alone. To achieve improved biocompatibility, the $\mathrm{Gd}_{2} \mathrm{O}_{3}$ :Eu nanoparti-

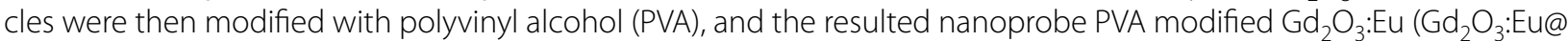
PVA) was applied in intraoperative tumor imaging. Compared with ${ }^{18} \mathrm{~F}-\mathrm{FDG}$ alone, intraoperative administration of $\mathrm{Gd}_{2} \mathrm{O}_{3}$ :Eu@PVA and ${ }^{18} \mathrm{~F}-\mathrm{FDG}$ combination achieved a much higher tumor-to-normal tissue ratio (TNR, $10.24 \pm 2.24$ vs. $1.87 \pm 0.73, P=0.0030$ ). The use of $\mathrm{Gd}_{2} \mathrm{O}_{3}$ :Eu@PVA and ${ }^{18} \mathrm{~F}-\mathrm{FDG}$ also assisted intraoperative detection of tumors that were omitted by preoperative positron emission tomography (PET) imaging. Further experiment of image-guided surgery demonstrated feasibility of image-guided tumor resection using $\mathrm{Gd}_{2} \mathrm{O}_{3}$ :Eu@PVA and ${ }^{18} \mathrm{~F}$-FDG. In summary, $\mathrm{Gd}_{2} \mathrm{O}_{3}$ :Eu can achieve significantly optimized imaging property when combined with ${ }^{18} \mathrm{~F}$-FDG in intraoperative tumor imaging and image-guided tumor resection surgery. It is expected that the development of the $\mathrm{Gd}_{2} \mathrm{O}_{3}$ :Eu nanoparticle will promote investigation and application of novel nanoparticles that can interact with radiopharmaceuticals for improved imaging properties. This work highlighted the impact of the nanoprobe that can be excited by radiopharmaceuticals emitting $\mathrm{CL}, \beta$, and $\gamma$ radiation for precisely imaging of tumor and intraoperatively guide tumor resection.
\end{abstract}

\footnotetext{
*Correspondence: jie.tian@ia.ac.cn; zhenhua.hu@ia.ac.cn

${ }^{1}$ CAS Key Laboratory of Molecular Imaging, Beijing Key Laboratory of Molecular Imaging, The State Key Laboratory of Management and Control for Complex Systems, Institute of Automation, Chinese Academy of Sciences, Beijing, China

Full list of author information is available at the end of the article
} permits use, sharing, adaptation, distribution and reproduction in any medium or format, as long as you give appropriate credit to the original author(s) and the source, provide a link to the Creative Commons licence, and indicate if changes were made. The images or other third party material in this article are included in the article's Creative Commons licence, unless indicated otherwise in a credit line to the material. If material is not included in the article's Creative Commons licence and your intended use is not permitted by statutory regulation or exceeds the permitted use, you will need to obtain permission directly from the copyright holder. To view a copy of this licence, visit http://creativecommons.org/licenses/by/4.0/. The Creative Commons Public Domain Dedication waiver (http://creativeco mmons.org/publicdomain/zero/1.0/) applies to the data made available in this article, unless otherwise stated in a credit line to the data. 
Keywords: Radiopharmaceuticals, $\mathrm{Gd}_{2} \mathrm{O}_{3}$ :Eu, Cerenkov luminescence imaging, Optical imaging, Image-guided surgery

\section{Introduction}

Cerenkov luminescence imaging (CLI) is an important optical imaging technique based on Cerenkov radiation generated along with the decay process of various radionuclides [1-4]. Numerous Food and Drug Administration (FDA)-approved radiopharmaceuticals that were originally used for positron emission computed tomography (PET) can generate Cerenkov luminescence (CL), providing CLI with high potential for clinical translation. Therefore, since the first biomedical imaging of small animals in 2009, CLI-based tumor imaging and image-guided tumor resection surgery have been broadly investigated in pre-clinical applications and also explored in clinic [5-14]. The combination of CLI and PET enables surgeon to achieve the distribution of the same imaging agent before and during surgery, which may provide surgeon with more information on the tumor location and improve the accuracy of the tumor resection surgery $[15,16]$. However, as optical signal intensity of CL is extremely weak, a long exposure time is often used in image acquisition. Besides, the ultraviolet-blue spectrum of the CL restricted penetration. These limit the application of CLI in intraoperative real-time tumor imaging.

Various fluorescent probes including small-molecule agents and nanoparticle (NP) probes have been combined with radiopharmaceuticals for improved imaging performances. Research has been focused on quantum dots (QDs) that can interact with $\mathrm{CL}$, achieving emitted light in the near-infrared range with deeper tissue-penetration. This imaging technique was named as radiation excited luminescence imaging [17] or the secondary Cerenkov emission fluorescence imaging (SCIFI) [18]. Another research has demonstrated that a clinically available imaging agent, fluorescein sodium (FS) which has been commonly used for retinal blood vessel imaging, can also be excited by Cerenkov photons for surgical navigation [19]. However, low photon fluence of CL greatly restricted it's interaction with fluorescent probes for in vivo imaging [20]. Therefore, novel imaging probes that can interact with radiopharmaceuticals through additional mechanisms have been desired. It was reported that the $\beta$ particles and $\gamma$ radiation generated along with the decay process of the radiopharmaceutical can also interact with some NPs [17, $21,22]$. These interactions can result in the ionization of the NP, with the fluorescence of higher signal intensity and longer wavelength emitted as the NP relaxes to the baseline state [23-27]. Therefore, the europium oxide $\left(\mathrm{Eu}_{2} \mathrm{O}_{3}\right) \mathrm{NP}$ that can be excited by $\mathrm{CL}$ and interact with $\gamma$ radiation as well has been developed to achieve an enhanced optical intensity and red-shifted optical spectrum of radiopharmaceuticals, which improves the tumor-to-normal tissue ratio (TNR) and shortens the exposure time [26-28]. Recently, $\mathrm{ZnGa}_{2} \mathrm{O}_{4}: \mathrm{Cr}^{3+} \mathrm{NPs}$ with persistent luminescence were reported to be activated by radiopharmaceuticals. The persistent luminescence of the NPs enabled long-lasting tumor detecting with high sensitivity and contrast $[29,30]$.

In this work, novel $\mathrm{Eu}^{3+}$ doped gadolinium oxide $\left(\mathrm{Gd}_{2} \mathrm{O}_{3}: \mathrm{Eu}\right)$ NPs were synthesized to be combined with radiopharmaceuticals for improved imaging performance. The commonly used clinical radiopharmaceutical 2-deoxy-2- ${ }^{18} \mathrm{~F}$-fluoroglucose $\left({ }^{18} \mathrm{~F}\right.$-FDG) was used to provide $C L, \beta$ particles, and $\gamma$ radiation. By mixing ${ }^{18}$ F-FDG and $\mathrm{Gd}_{2} \mathrm{O}_{3}: \mathrm{Eu}$ NPs, an enhanced red-shifted emission light was achieved. It was found that $\mathrm{Gd}_{2} \mathrm{O}_{3}$ :Eu NPs interact with $\mathrm{CL}, \beta$, and $\gamma$ radiation, which turned the energy of radiopharmaceuticals into fluorescence with high efficiency. Therefore, the imaging method was named as triple-excited fluorescence imaging (TEFI). Moreover, $\mathrm{Gd}_{2} \mathrm{O}_{3}$ :Eu NPs were modified by polyvinyl alcohol (PVA) for improvement of biocompatibility. In the end, performance of PVA modified $\mathrm{Gd}_{2} \mathrm{O}_{3}: \mathrm{Eu}\left(\mathrm{Gd}_{2} \mathrm{O}_{3}\right.$ :Eu@PVA) on tumor imaging and image-guided surgery were evaluated using subcutaneous breast tumor-bearing mouse models. It was demonstrated that $\mathrm{Gd}_{2} \mathrm{O}_{3}: \mathrm{Eu} @ P V A$ and ${ }^{18} \mathrm{~F}$-FDG combination improved intraoperative tumor detection with a high imaging contrast.

\section{Materials and methods \\ Synthesis of $\mathrm{Gd}_{2} \mathrm{O}_{3}$ :Eu NPs}

The hydrothermal method was used in the synthesis of $\mathrm{Gd}_{2} \mathrm{O}_{3}: \mathrm{Eu}$ NPs referring to the previous report [31]. $1.52 \mathrm{mmol} \mathrm{Gd}\left(\mathrm{NO}_{3}\right)_{3} \cdot 9 \mathrm{H}_{2} \mathrm{O}, 0.08 \mathrm{mmol} \mathrm{Eu}\left(\mathrm{NO}_{3}\right)_{3} \cdot 6 \mathrm{H}_{2} \mathrm{O}$, and $0.2168 \mathrm{~g}$ urea were mixed with $8 \mathrm{~mL}$ of deionized water (DI water) and different amount of glycerol. The mixture was stirred until the solution turned clear and was then transferred into a stainless-steel reactor. The reaction lasted $500 \mathrm{~min}$ under $160{ }^{\circ} \mathrm{C}$. After the reaction, the solution was cooled and centrifugated. The product was washed with DI water three times. The product was then dried using a lyophilizer at $-60{ }^{\circ} \mathrm{C}$ under vacuum. The dried precipitate was calcinated at $1000{ }^{\circ} \mathrm{C}$ for another $4 \mathrm{~h}$. The dose of glycerol was regulated to achieve $\mathrm{Gd}_{2} \mathrm{O}_{3}$ :Eu NPs of different sizes. Glycerol $(3,1$, or $0.5 \mathrm{~mL})$ 
was added to obtain $\mathrm{Gd}_{2} \mathrm{O}_{3}$ : Eu with a diameter of 50, 100, and $200 \mathrm{~nm}$ (named as $\mathrm{Gd}_{2} \mathrm{O}_{3}: \mathrm{Eu}-50, \mathrm{Gd}_{2} \mathrm{O}_{3}: \mathrm{Eu}-100$, and $\left.\mathrm{Gd}_{2} \mathrm{O}_{3}: \mathrm{Eu}-200\right)$, respectively.

\section{PVA modification of NPs}

To modify the NPs with PVA, $\mathrm{Gd}_{2} \mathrm{O}_{3}: \mathrm{Eu}-50$, $\mathrm{Gd}_{2} \mathrm{O}_{3}: \mathrm{Eu}-100$, and $\mathrm{Gd}_{2} \mathrm{O}_{3}: \mathrm{Eu}-200$ were added into the DI water solution of PVA separately. The mixture of the $\mathrm{Gd}_{2} \mathrm{O}_{3}$ :Eu NPs and PVA were stirred using quartz beads to ensure that the $\mathrm{Gd}_{2} \mathrm{O}_{3}:$ Eu NPs were uniformly coated with PVA and formed $\mathrm{Gd}_{2} \mathrm{O}_{3}: \mathrm{Eu}-50, \mathrm{Gd}_{2} \mathrm{O}_{3}$ :Eu-100, and $\mathrm{Gd}_{2} \mathrm{O}_{3}$ :Eu-200 modified with PVA $\left(\mathrm{Gd}_{2} \mathrm{O}_{3}\right.$ :Eu-50@PVA, $\mathrm{Gd}_{2} \mathrm{O}_{3}: \mathrm{Eu}-100 @ P V A$, and $\left.\mathrm{Gd}_{2} \mathrm{O}_{3}: \mathrm{Eu}-200 @ P V A\right)$. The mixture was then dried using a lyophilizer at $-60{ }^{\circ} \mathrm{C}$ under vacuum.

\section{Characterization of $\mathrm{Gd}_{2} \mathrm{O}_{3}$ :Eu and $\mathrm{Gd}_{2} \mathrm{O}_{3}$ :Eu@PVA NPs}

The size and morphology of $\mathrm{Gd}_{2} \mathrm{O}_{3}$ :Eu NPs were tested by Transmission Electron Microscope (TEM, JEOL Ltd, Tokyo, Japan). The diameters of the NPs were measured with Image $J$ according to the TEM images (National Institutes of Health, Maryland, USA). Fluorescent properties including emission and excitation spectra were measured using EnSpire Multimode Plate Readers (PerkinElmer, Inc., Massachusetts, USA). The crystal characteristics of the nanoparticles were tested with an Ultima IV X-ray diffractometer (XRD, Rigaku, Tokyo, Japan). X-ray photoelectron spectroscopy (XPS) measurements were carried out with Thermo Scientific K-Alpha + (Thermo Fisher Scientific, Massachusetts, USA).

\section{Fluorescence imaging}

The fluorescence images were acquired with the IVIS Spectrum imaging system (PerkinElmer, Inc., Massachusetts, USA). In the experiments on the influencing factors of optical signal intensity of $\mathrm{Gd}_{2} \mathrm{O}_{3}$ : Eu NPs, an exposure time of $60 \mathrm{~s}$ was adopted. While in the in vitro experiments to verify the interaction type, an exposure time of $300 \mathrm{~s}$ was adopted. To evaluate the spectrum of the emitted light, a series of bandpass filters with a discrete center wavelength from 500 to $840 \mathrm{~nm}$ integrated into the IVIS system was adopted with an exposure time of $20 \mathrm{~s}$. For the experiments on tissue penetration, an open filter was applied, with the exposure time set to be $5 \mathrm{~s}$. In the animal experiments of phantom study, imaging, and imageguided surgery, an open filter and an exposure time of 300 s were used.

\section{Investigation of the factors affecting radical interaction}

To select the most suitable NP for biomedical imaging, $5 \mathrm{mg} \mathrm{Gd}_{2} \mathrm{O}_{3}: \mathrm{Eu}-50, \mathrm{Gd}_{2} \mathrm{O}_{3}: \mathrm{Eu}-100, \mathrm{Gd}_{2} \mathrm{O}_{3}: \mathrm{Eu}-200$, $\mathrm{Gd}_{2} \mathrm{O}_{3}:$ Eu-50@PVA, $\quad \mathrm{Gd}_{2} \mathrm{O}_{3}$ :Eu-100@PVA, or $\mathrm{Gd}_{2} \mathrm{O}_{3}: \mathrm{Eu}-200 @ P V A$ were set in 6 different Eppendorf
(EP) tubes and mixed with ${ }^{18} \mathrm{~F}$-FDG $(430 \mu \mathrm{Ci}, 100 \mu \mathrm{l})$, respectively. Images of the $6 \mathrm{EP}$ tubes were acquired to evaluate the signal intensity. $\mathrm{Gd}_{2} \mathrm{O}_{3}: \mathrm{Eu}$ and $\mathrm{Gd}_{2} \mathrm{O}_{3}: \mathrm{Eu} @$ PVA with a diameter of $100 \mathrm{~nm}$ were selected for the following ex vivo and in vivo experiments based on the aforementioned experimental results.

To investigate the impact of distance between the excitation source $\left({ }^{18} \mathrm{~F}\right.$-FDG) and the NP $\left(\mathrm{Gd}_{2} \mathrm{O}_{3}\right.$ : $\left.\mathrm{Eu}\right)$ on the optical intensity produced, a single well of a transparent 96-well plate loaded with ${ }^{18} \mathrm{~F}$-FDG $(730 \mu \mathrm{Ci}, 100 \mu \mathrm{l})$, and an EP tube containing $\mathrm{Gd}_{2} \mathrm{O}_{3}: \mathrm{Eu}-100(20 \mathrm{mg})$ was placed with the distance between the bottom of the tube and the well set to be $10,20,30,40$, and $50 \mathrm{~mm}$. The signal intensity of $\mathrm{Gd}_{2} \mathrm{O}_{3}: \mathrm{Eu}-100 \mathrm{NP}$ on each image was measured, and its correlation with distance was then determined.

To evaluate impact of radioactivity, a series of EP tubes containing $100 \mu \mathrm{l}$ of ${ }^{18} \mathrm{~F}$-FDG with different radioactivity $(1128,552,285,145,73,36,18,9,4$, and $2 \mu \mathrm{Ci})$ were applied as excitation source successively. $\mathrm{Gd}_{2} \mathrm{O}_{3}: \mathrm{Eu}-100$ (20 mg) was placed in another EP tube. The distance between them was set to be $10 \mathrm{~mm}$. The signal intensity of the $\mathrm{Gd}_{2} \mathrm{O}_{3}: \mathrm{Eu}-100 \mathrm{NP}$ was measured and correlated to the radioactivity of the ${ }^{18} \mathrm{~F}-\mathrm{FDG}$ in each image.

To assess the impact of mass, ${ }^{18} \mathrm{~F}$-FDG $(730 \mu \mathrm{Ci}$, $100 \mu \mathrm{l})$ was set in a well of a transparent 96-well plate. $\mathrm{Gd}_{2} \mathrm{O}_{3}: \mathrm{Eu}-100$ with different mass $(20,10,5,2.5,1 \mathrm{mg})$ was placed in EP tubes, respectively. The distance between the well and the tubes was $10 \mathrm{~mm}$. the signal intensity of each EP tube containing $\mathrm{Gd}_{2} \mathrm{O}_{3}$ :Eu-100 with different mass was measured and correlated to the mass.

$\mathrm{Eu}_{2} \mathrm{O}_{3}$ of the same mass with $\mathrm{Gd}_{2} \mathrm{O}_{3}$ : Eu was used as a comparison in each experiment as stated above.

\section{Investigation of interaction mechanisms between $\mathrm{Gd}_{2} \mathrm{O}_{3}$ :Eu and ${ }^{18} \mathrm{~F}$-FDG}

To reveal the mechanisms that result in the emission of light, $\mathrm{Gd}_{2} \mathrm{O}_{3}: \mathrm{Eu}-100$ powder $(20 \mathrm{mg})$ and ${ }^{18} \mathrm{~F}-\mathrm{FDG}$ $(2.2 \mathrm{mCi}, 100 \mu \mathrm{l})$ were placed at the bottom of two EP tubes. Images were first acquired when the bottom of the two EP tubes was placed next to each other, with no blocking between them. Therefore, the $C L, \beta$ particle and $\gamma$ radiation generated from ${ }^{18} \mathrm{~F}$-FDG can all interact with $\mathrm{Gd}_{2} \mathrm{O}_{3}: \mathrm{Eu}-100$. An aluminum plate that blocked $\mathrm{CL}$ and $\beta$ particles and a lead plate that blocked $C L, \beta$ particles, and $\gamma$ radiation were then placed between the two tubes in order. Black tapes were then used to cover the EP tube containing ${ }^{18} \mathrm{~F}-\mathrm{FDG}$ to block $\mathrm{CL}$ only. Images were acquired in each step. Besides, to further investigate the contribution of $\mathrm{CL}$ to the emission, the two EP tubes containing ${ }^{18} \mathrm{~F}$-FDG and $\mathrm{Gd}_{2} \mathrm{O}_{3}: \mathrm{Eu}-100$ were placed with the bottom $20 \mathrm{~mm}$ apart. Two mirrors were placed on both sides of the tubes to reflect CL. Optical images were acquired to reveal the three types of interaction with $\mathrm{CL}$, 
$\beta$ particle, and $\gamma$ radiation. With a lead plate set between the two tubes, $\beta$ particles and $\gamma$ radiation were blocked, where only CL can interact with the $\mathrm{Gd}_{2} \mathrm{O}_{3}$ : $\mathrm{Eu}-100$. Optical images were then acquired for evaluation of light emission caused by CL. The same operation was repeated with $\mathrm{Gd}_{2} \mathrm{O}_{3}: \mathrm{Eu}-100$ replaced by $\mathrm{Eu}_{2} \mathrm{O}_{3}$ powder $(20 \mathrm{mg})$ to investigate the contribution of $\mathrm{CL}$ to the emission when the $\mathrm{Eu}_{2} \mathrm{O}_{3} \mathrm{NP}$ was used.

\section{Assessment of emission spectrum and tissue penetration ability of the light}

$\mathrm{Gd}_{2} \mathrm{O}_{3}: \mathrm{Eu}, \mathrm{Gd}_{2} \mathrm{O}_{3}: \mathrm{Eu} @ P V A$ of different sizes $(50,100$, and $200 \mathrm{~nm}$ ) and $\mathrm{Eu}_{2} \mathrm{O}_{3}$ (powder, each $5 \mathrm{mg}$ ) were mixed with ${ }^{18} \mathrm{~F}$-FDG $(430 \mu \mathrm{Ci}, 100 \mu \mathrm{l})$ separately in a well of the 96 -well plate. Saline solution $(100 \mu \mathrm{l})$ and ${ }^{18} \mathrm{~F}$-FDG $(430 \mu \mathrm{Ci}, 100 \mu \mathrm{l})$ were used as the control. The penetration ability of the light emitted from the mixtures in biological tissue was then evaluated using a porcine intestine covering the 96-well plate.

\section{Cell culturing and animal model establishment}

All the experimental procedures involving animals were approved by the Institutional Animal Care and Use Committee of the Fifth Affiliated Hospital, Sun Yat-sen University (2020071401). 4T1 mouse mammary tumor cells were cultured with RPMI 1640 medium (Gibco, Life Technologies, Carlsbad, CA) supplemented with $10 \%$ fetal bovine serum (FBS, Gibco, Life Technologies, Carlsbad, CA), $100 \mathrm{U} / \mathrm{mL}$ penicillin and $100 \mu \mathrm{g} / \mathrm{ml}$ streptomycin (Life Technologies, Carlsbad, CA) in a humidified incubator at $37{ }^{\circ} \mathrm{C}$ with $5 \% \mathrm{CO}_{2}$.

Female balb/c nude mice of 4 weeks (Beijing Vital River Laboratory Animal Technology Co. Ltd, Beijing, China) were used in this study. The subcutaneous breast cancer mice models were established by injecting $5 \times 10^{6} 4 \mathrm{~T} 1$ mouse mammary tumor cells subcutaneously in mice. Seven days after injection, the mice were used for imaging and image-guided surgery experiment. Animal surgery and imaging were performed under isoflurane gas anesthesia (3\% isoflurane and air mixture), and all the possible actions were employed to minimize the suffering of the mice.

\section{In vivo optical imaging using capillary phantoms}

Two capillaries were subcutaneously embedded into the back of the athymic nude mouse. One capillary was filled with ${ }^{18} \mathrm{~F}$-FDG $(84 \mu \mathrm{Ci}, 20 \mu \mathrm{l})$, while the other was filled with the mixture of $\mathrm{Gd}_{2} \mathrm{O}_{3}$ :Eu@PVA $(2 \mathrm{mg})$ and ${ }^{18} \mathrm{~F}$-FDG $(84 \mu \mathrm{Ci}, 20 \mu \mathrm{l})$. PET and optical imaging were performed for comparison.
In vivo evaluation of the $\mathrm{Gd}_{2} \mathrm{O}_{3}: \mathrm{Eu}-100 @ \mathrm{PVA}$ and ${ }^{18} \mathrm{~F}-\mathrm{FDG}$ mixture

To study the performance of $\mathrm{Gd}_{2} \mathrm{O}_{3}$ :Eu-100@PVA in improving the optical signal intensity of ${ }^{18} \mathrm{~F}-\mathrm{FDG}$ in vivo, breast tumor-bearing mice $(\mathrm{n}=8)$ were randomly assigned to the TEFI and CLI group $(n=4$ for each group). For the TEFI group, mice were injected intravenously with ${ }^{18} \mathrm{~F}-\mathrm{FDG}(250 \mu \mathrm{Ci}, 200 \mu \mathrm{l})$ and $\mathrm{Gd}_{2} \mathrm{O}_{3}: \mathrm{Eu}-100 @ P V A(1 \mathrm{mg} / \mathrm{ml}, 100 \mu \mathrm{l})$, while the mice in the CLI group were injected with only ${ }^{18} \mathrm{~F}$-FDG $(1 \mathrm{mg} /$ $\mathrm{ml}, 100 \mu \mathrm{l})$. Imaging was performed $1.5 \mathrm{~h}$ after injection using the IVIS system.

\section{PET imaging of small animals}

Static 5-min PET images of animals injected with ${ }^{18} \mathrm{~F}$ FDG were acquired using a preclinical PET/CT scanner (Genisys PET, SofieBiosciences, Inc., USA). The data acquisition mode of ${ }^{18} \mathrm{~F}$ was integrated into the device.

\section{Biodistribution of $\mathrm{Gd}_{2} \mathrm{O}_{3}:$ Eu@PVA}

The tumor-bearing mice in the TEFI group were euthanized immediately after NPs based optical imaging. The tumor, heart, liver, spleen, lung, kidney, intestine, brain, and muscle were harvested, and blood was also collected for ex vivo optical imaging.

\section{Results}

The characteristic of the synthesized $\mathrm{Gd}_{2} \mathrm{O}_{3}$ :Eu NPs

The size of $\mathrm{Gd}_{2} \mathrm{O}_{3}: \mathrm{Eu}-50, \mathrm{Gd}_{2} \mathrm{O}_{3}: \mathrm{Eu}-100$, and $\mathrm{Gd}_{2} \mathrm{O}_{3}: \mathrm{Eu}-200$ NPs was in ranges of $50-75,90-110$, and $170-230 \mathrm{~nm}$, respectively (Fig. 1a-c), as measured on the TEM images. The surface modification with PVA did not significantly change the size and morphology of $\mathrm{Gd}_{2} \mathrm{O}_{3}: \mathrm{Eu}$ NPs, with the diameters laid in ranges of 65-88, 95-116, and 195-244 nm (Fig. 1d-f).

The excitation spectrum showed that the maximum excitation wavelength of the NPs, including $\mathrm{Gd}_{2} \mathrm{O}_{3}: \mathrm{Eu}$ and $\mathrm{Gd}_{2} \mathrm{O}_{3}: \mathrm{Eu} @ P V A$ with different diameters $(50,100$, $200 \mathrm{~nm}$ ) was $308 \mathrm{~nm}$, with a smaller peak laying on around $214 \mathrm{~nm}$ (Fig. 1g). When excited by $308 \mathrm{~nm}$ excitation light, the emission peak was $620 \mathrm{~nm}$ for all the NPs (Fig. 1h). When excited by $214 \mathrm{~nm}$ excitation light, the emission spectrum had three peaks lying on 460,620 , and $700 \mathrm{~nm}$ (Fig. 1i).

The peaks of the XPS spectrum at the 141.98 and $1134.48 \mathrm{eV}$ binding energy proved the presence of the $\mathrm{Gd}$ and $\mathrm{Eu}$ (Fig. 1j, k). The XRD spectrum of the $\mathrm{Gd}_{2} \mathrm{O}_{3}:$ Eu-100 NP was matched with the standard JCPDS 12-0797 card. The XRD peaks were related only to the $\mathrm{Gd}_{2} \mathrm{O}_{3}$ nanoparticles (Fig. 11). 

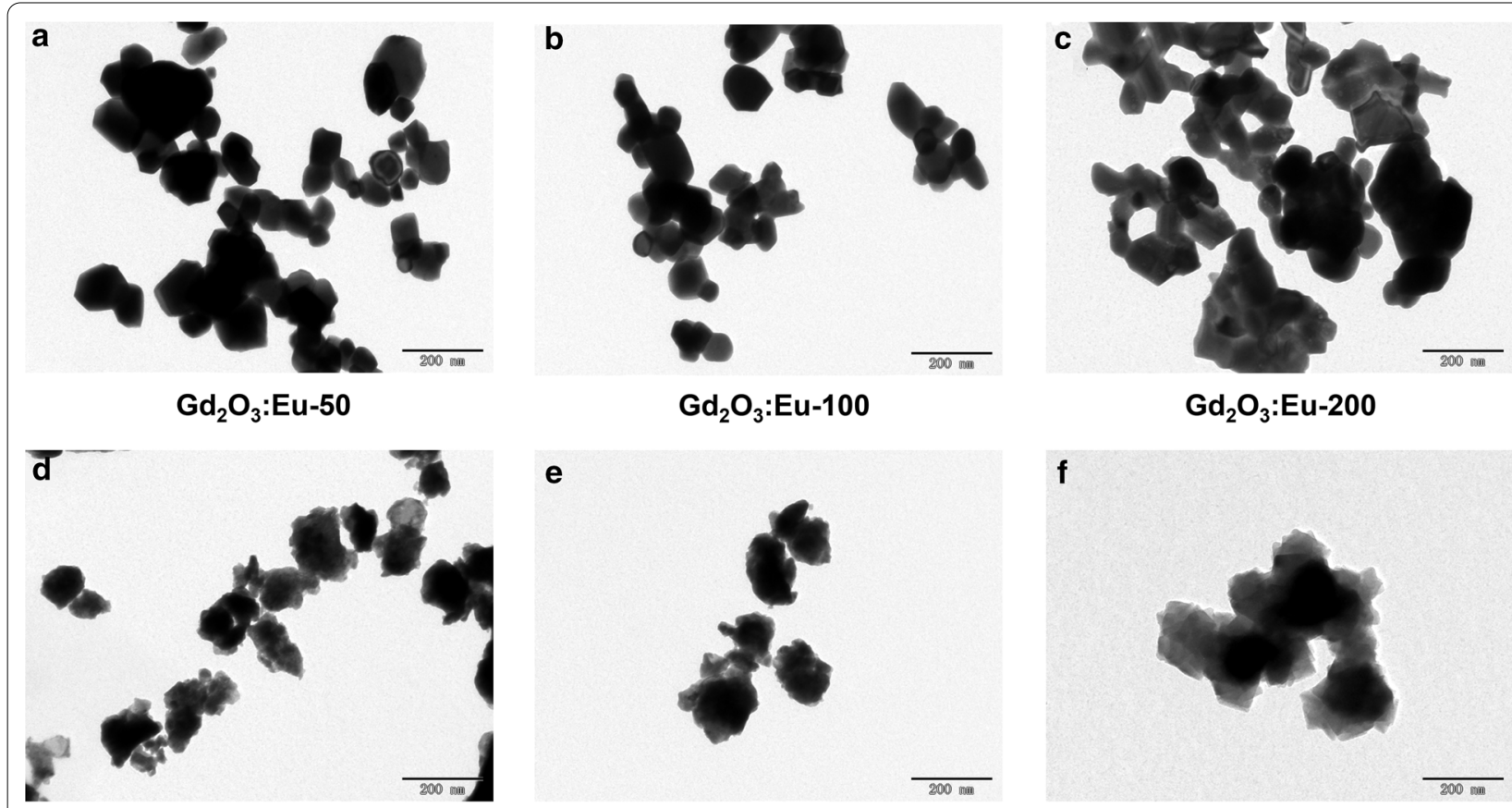

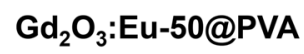

\section{$\mathrm{Gd}_{2} \mathrm{O}_{3}: \mathrm{Eu}-100 @ P V A$}

h

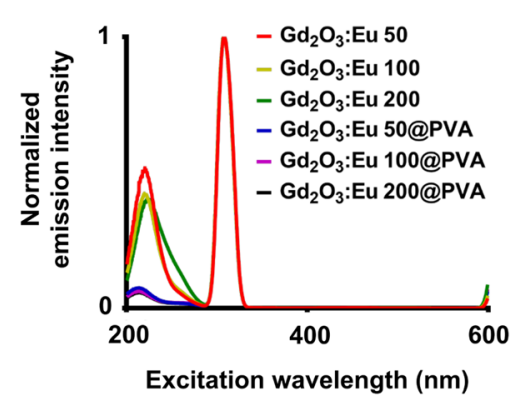

j

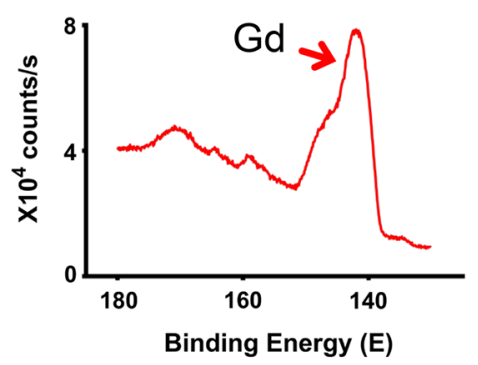

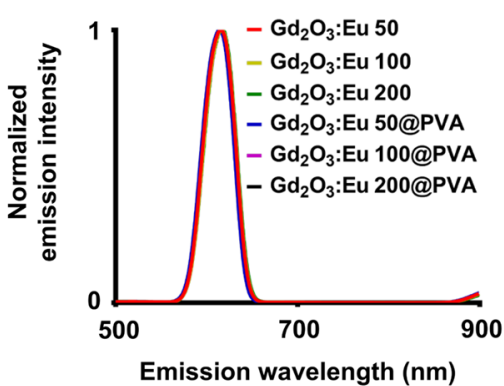

k

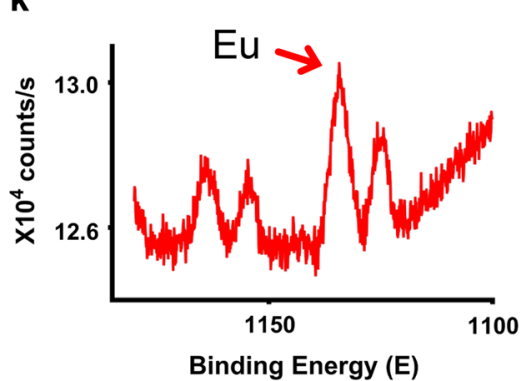

$\mathrm{Gd}_{2} \mathrm{O}_{3}: \mathrm{Eu}-200 @ P V A$

i

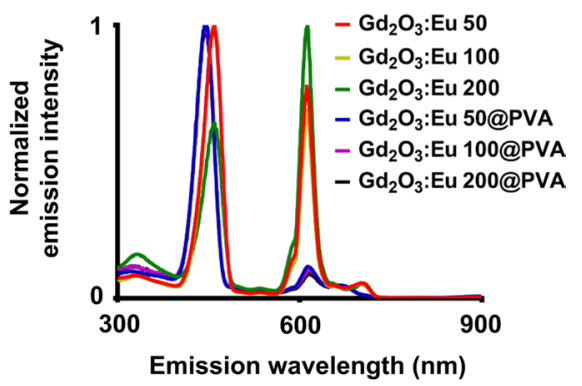

I

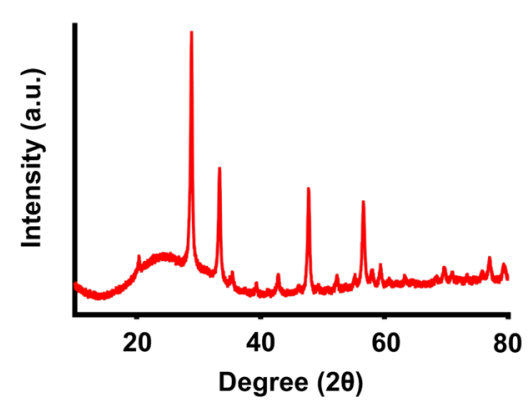

Fig. 1 Nanoparticle morphology and spectrum. a-f the TEM images of the NPs with different sizes and surface modification. Scale bar, $200 \mathrm{~nm}$. $\mathbf{g}$ the excitation peaks lays on 214 and $308 \mathrm{~nm}$, keeping the emission fixed at $620 \mathrm{~nm}$. $\mathbf{h}$ an emission peak of $620 \mathrm{~nm}$ was displayed under $214 \mathrm{~nm}$ excitation. $\mathbf{i}$ emission peaks of $460 \mathrm{~nm}, 620 \mathrm{~nm}$, and $700 \mathrm{~nm}$ were displayed under $308 \mathrm{~nm}$ excitation light. $\mathbf{j}, \mathbf{k}$ the XPS spectrum of Gd (j) and Eu (k) from the $\mathrm{Gd}_{2} \mathrm{O}_{3}:$ Eu-100 NP. I XRD patterns of the $\mathrm{Gd}_{2} \mathrm{O}_{3}: \mathrm{Eu}-100 \mathrm{NP}$

The influential factors of optical signal intensity

The optical signal intensity of the NPs was affected by the particle size and surface modification (Fig. 2a, b).
For $\mathrm{Gd}_{2} \mathrm{O}_{3}$ :Eu without surface modification of PVA, the optical signal intensity decreased as the particle size increased, with the $\mathrm{Gd}_{2} \mathrm{O}_{3}: \mathrm{Eu}-50$ generating light with 

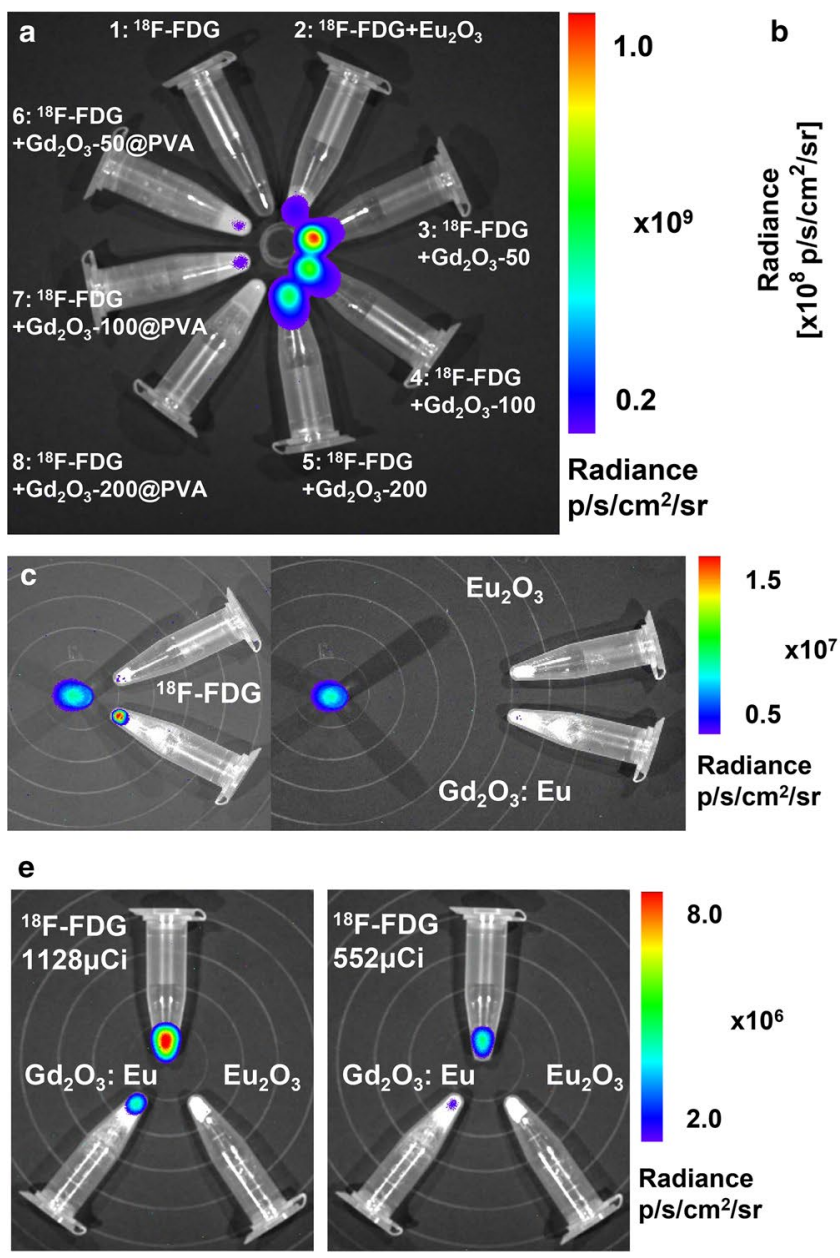

g
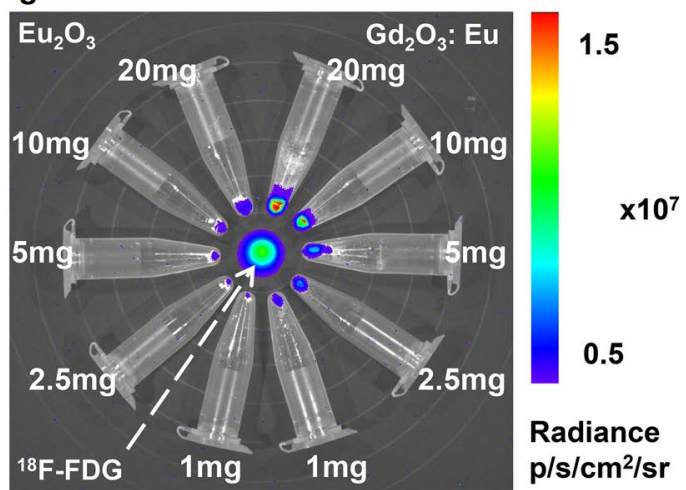

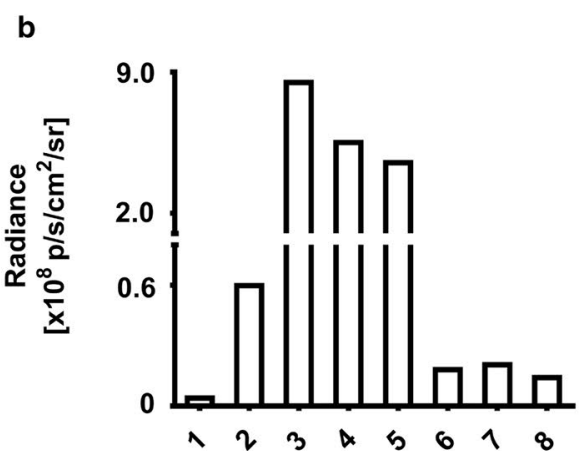

d

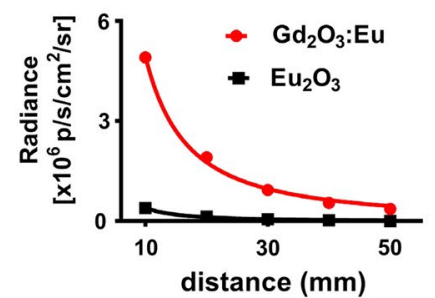

f

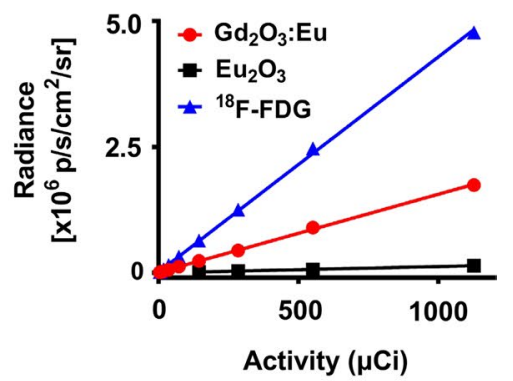

$\mathbf{h}$

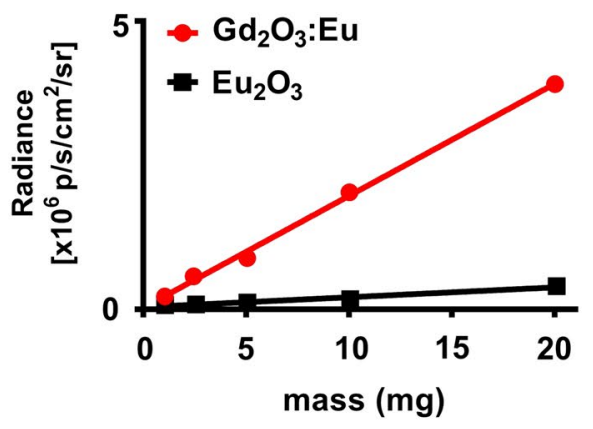

Fig. 2 The factors impacting the optical signal intensity of interaction. a,b, optical images (a) and quantitative analysis (b) displayed that the size and surface modification of the NPs affected the optical signal intensity. $\mathbf{c}$, $\mathbf{d}$ the optical signal intensity is in inverse proportion to the interaction distance between $\mathrm{Gd}_{2} \mathrm{O}_{3}: \mathrm{Eu}-100 / \mathrm{Eu}_{2} \mathrm{O}_{3}$ and ${ }^{18} \mathrm{~F}-\mathrm{FDG}$. e, $\mathbf{f}$ the optical signal intensity is in direct proportion to the radioactivity of ${ }^{18} \mathrm{~F}-\mathrm{FDG}$. $\mathbf{g}, \mathbf{h}$ the optical signal intensity is in direct proportion to the mass of the $\mathrm{Gd}_{2} \mathrm{O}_{3}: \mathrm{Eu} / \mathrm{Eu}_{2} \mathrm{O}_{3}$

the highest optical signal intensity and $\mathrm{Gd}_{2} \mathrm{O}_{3}: \mathrm{Eu}-200$ generating light with the lowest optical signal intensity. For $\mathrm{Gd}_{2} \mathrm{O}_{3}$ :Eu with surface modification by PVA,
$\mathrm{Gd}_{2} \mathrm{O}_{3}: \mathrm{Eu}-100 @ P V A$ generated light with the highest optical signal intensity while $\mathrm{Gd}_{2} \mathrm{O}_{3}$ : Eu-200@PVA generated light with the lowest optical signal intensity. 
As the mass of the particles used were kept the same, the amount of the $\mathrm{Gd}_{2} \mathrm{O}_{3}$ :Eu may be replaced by PVA. Therefore the optical signal was influenced by PVA modification though it may improve biocompatibility. With the results obtained above, the $100 \mathrm{~nm}$ NPs were further evaluated in the following experiments, with $\mathrm{Gd}_{2} \mathrm{O}_{3}: \mathrm{Eu}-100 @ P V A$ used in the in vivo experiments and $\mathrm{Gd}_{2} \mathrm{O}_{3}: \mathrm{Eu}-100$ tested in the ex vivo experiments.

The influencing factors of the optical signal intensity also included excitation distance, the amount of the radioactivity of ${ }^{18} \mathrm{~F}$-FDG, and the mass of NPs $\left(\mathrm{Gd}_{2} \mathrm{O}_{3}: \mathrm{Eu}-100\right.$ and $\left.\mathrm{Eu}_{2} \mathrm{O}_{3}\right)$. The optical signal intensity decreased exponentially as the excitation distance increased for both $\mathrm{Gd}_{2} \mathrm{O}_{3}$ :-Eu-100 and $\mathrm{Eu}_{2} \mathrm{O}_{3}$, with $\mathrm{R}^{2}$ of 0.9972 for $\mathrm{Gd}_{2} \mathrm{O}_{3}: \mathrm{Eu}-100$ and 0.9931 for $\mathrm{Eu}_{2} \mathrm{O}_{3}$ (Fig. 2c, d, Additional file 1: Fig. S1a). The optical signal intensity of the NP increased linearly with the increasing of the radioactivity of ${ }^{18} \mathrm{~F}$-FDG, with $\mathrm{R}^{2}$ of 0.9994 for $\mathrm{Gd}_{2} \mathrm{O}_{3}$ :- $\mathrm{Eu}$ and 0.9998 for $\mathrm{Eu}_{2} \mathrm{O}_{3}$ (Fig. 2e, f, Additional file 1: Fig. S1b). As for the mass of NPs, the optical signal intensity of the NPs also increased linearly with the mass of NPs, with $\mathrm{R}^{2}$ of 0.9975 for $\mathrm{Gd}_{2} \mathrm{O}_{3}: \mathrm{Eu}$ and 0.9737 for $\mathrm{Eu}_{2} \mathrm{O}_{3}$ (Fig. 2g, h). The optical signal of $\mathrm{Gd}_{2} \mathrm{O}_{3}$ :Eu was much higher than that of $\mathrm{Eu}_{2} \mathrm{O}_{3}$ in each of the studies.

\section{Investigation of the optical signal caused by $\mathrm{CL}, \beta$ particles,} and $\gamma$ radiation of ${ }^{18} \mathrm{~F}-\mathrm{FDG}$

It was observed that emission light was generated by $\mathrm{Gd}_{2} \mathrm{O}_{3}:$ Eu 100 through interactions with $\mathrm{CL}, \beta$ particle, and $\gamma$ radiation generated by ${ }^{18}$ F-FDG (Fig. 3a). The overall optical signal intensity caused by all three types of interactions was set to be $100 \%$ (Fig. 3a row I and Fig. 3b I). With only CL blocked by black tape, the optical signal caused by interaction with $\beta$ particles and $\gamma$ radiation was observed, which accounted for $68.04 \%$ of the overall optical signal intensity (Fig. 3a row II and Fig. 3b II). With CL and $\beta$ particles both blocked by an aluminum plate, the optical signal caused by interaction with $\gamma$ radiation was acquired, which only accounted for $27.30 \%$ of the overall optical signal intensity (Fig. 3a row III and Fig. 3b III). In the further experiment where $C L, \beta$, and $\gamma$ radiation were all blocked by a lead plate, the optical signal was barely acquired (Fig. 3a row IV and Fig. 3b IV). It was calculated that $31.97 \%$ of the optical signal was caused by $C L, 40.74 \%$ of the optical signal was caused by $\beta$ particles, and $27.30 \%$ was caused by $\gamma$ radiation. Moreover, with $\beta$ particles and $\gamma$ radiation blocked by a lead plate, but CL reflected by two mirrors, the optical signal caused by interaction with $\mathrm{CL}$ was evaluated independently (Fig. 3c-f). For $\mathrm{Gd}_{2} \mathrm{O}_{3}$ :Eu-100, 35.27\% of the optical signal was caused by CL, which was in accordance with the result of the experiments above (Fig. 3c, d). For $\mathrm{Eu}_{2} \mathrm{O}_{3}$, the previously reported radiopharmaceutical excitable
NP, $43.07 \%$ of the optical signal was caused by CL according to measurement (Fig. 3e, f).

\section{Characterization and tissue penetration of the red-shifted emission light}

The $5 \mathrm{mg}$ NPs $\left(\mathrm{Eu}_{2} \mathrm{O}_{3}, \mathrm{Gd}_{2} \mathrm{O}_{3}: \mathrm{Eu}\right.$, and $\left.\mathrm{Gd}_{2} \mathrm{O}_{3}: \mathrm{Eu} @ P V A\right)$ extensively enhanced the optical signal intensity and tissue penetration capacity of ${ }^{18} \mathrm{~F}$-FDG (Fig. 4). The optical image acquired with an open filter demonstrated that the signal intensity of the mixture of $\mathrm{Gd}_{2} \mathrm{O}_{3}$ : Eu NPs (with diameters of 50, 100, and $200 \mathrm{~nm}$ ) and ${ }^{18} \mathrm{~F}$-FDG were all higher than that of ${ }^{18} \mathrm{~F}$-FDG alone and the mixture of $\mathrm{Eu}_{2} \mathrm{O}_{3}$ and ${ }^{18} \mathrm{~F}$-FDG. It was demonstrated that the optical signal intensity of the novel $\mathrm{Gd}_{2} \mathrm{O}_{3}$ :Eu-50 NPs was 16.19 times higher than that of $\mathrm{Eu}_{2} \mathrm{O}_{3}$ when mixed with ${ }^{18} \mathrm{~F}$-FDG, and reached 369 times higher than that of ${ }^{18} \mathrm{~F}$ FDG alone (Fig. 4a). The emission peak of the emission light measured using bandpass filters also laid on 620 and $700 \mathrm{~nm}$, which was in accordance with the spectrum measured using a spectrometer previously (Fig. 4b). Images acquired with a $620 \mathrm{~nm}$ filter demonstrated that the optical signal intensity of $\mathrm{Gd}_{2} \mathrm{O}_{3}: \mathrm{Eu}-50$ was the highest, followed by the $\mathrm{Gd}_{2} \mathrm{O}_{3}: \mathrm{Eu}-100$, and $\mathrm{Gd}_{2} \mathrm{O}_{3}: \mathrm{Eu}-200$ (Fig. 4c, d). While mentioning the $\mathrm{Gd}_{2} \mathrm{O}_{3}$ :Eu NPs modified by PVA, it was the same case that $\mathrm{Gd}_{2} \mathrm{O}_{3}$ :Eu-50@PVA possessed the emission light with the highest intensity, followed by $\mathrm{Gd}_{2} \mathrm{O}_{3}$ :-Eu-100@PVA and $\mathrm{Gd}_{2} \mathrm{O}_{3}: \mathrm{Eu}-200 @$ PVA (Fig. 4c, d). However, when it came to the $700 \mathrm{~nm}$ filter, the $\mathrm{Gd}_{2} \mathrm{O}_{3}: \mathrm{Eu}-100$ possessed the highest optical signal intensity (Fig. 4e, f). Therefore, for $\mathrm{Gd}_{2} \mathrm{O}_{3}$ :Eu with surface modification, with the relatively weak optical signal of $620 \mathrm{~nm}$ wavelength, the accumulated optical signal of a broad spectrum of $\mathrm{Gd}_{2} \mathrm{O}_{3}$ :Eu-100@PVA was the highest among $\mathrm{Gd}_{2} \mathrm{O}_{3}$ :Eu NPs with surface modification.

With a porcine intestine covered on the top, the $\mathrm{CL}$ of the ${ }^{18}$ F-FDG was nearly blanketed and almost unmeasurable. Whereas the optical signal of the NPs and ${ }^{18} \mathrm{~F}$ FDG mixtures were rather higher. The $\mathrm{Gd}_{2} \mathrm{O}_{3}: \mathrm{Eu}-50$ showed the highest optical signal intensity among the three $\mathrm{Gd}_{2} \mathrm{O}_{3}$ :Eu-NPs with different diameters. While $\mathrm{Gd}_{2} \mathrm{O}_{3}$ :-Eu-100@PVA showed the highest optical signal intensity among the three $\mathrm{Gd}_{2} \mathrm{O}_{3}$ :Eu NPs with surface modification (Fig. 4g, h).

\section{Validation using in vivo capillary phantom and living animal models}

With the living phantom established using capillaries that contained ${ }^{18} \mathrm{~F}$-FDG or ${ }^{18} \mathrm{~F}$-FDG mixed with $\mathrm{Gd}_{2} \mathrm{O}_{3}:$ Eu-100@PVA, the feasibility of the in vivo use of $\mathrm{Gd}_{2} \mathrm{O}_{3}:$ Eu-100@PVA NP was investigated. The PET image showed an equal signal intensity of the two implanted tubes, indicating similar radioactivity of ${ }^{18} \mathrm{~F}$-FDG in the two capillaries (Fig. 5a). Nevertheless, the optical signal 

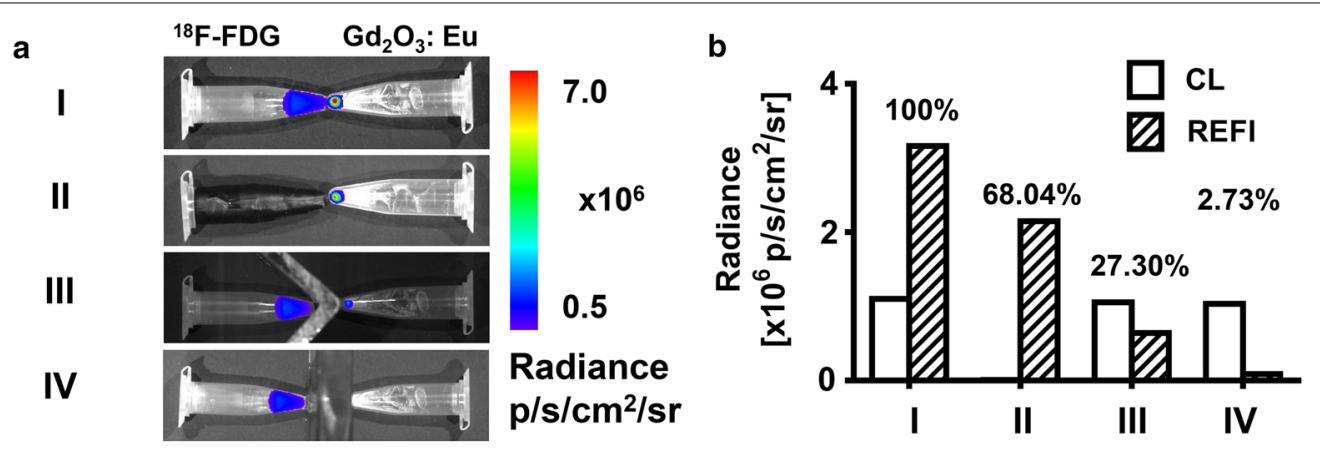

C

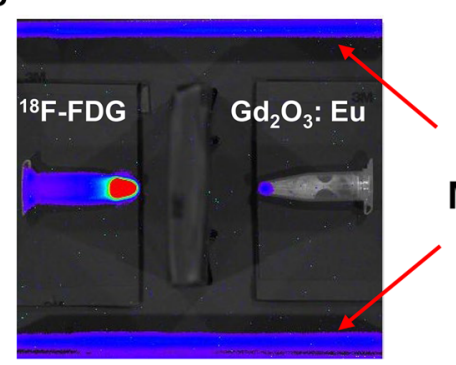

d

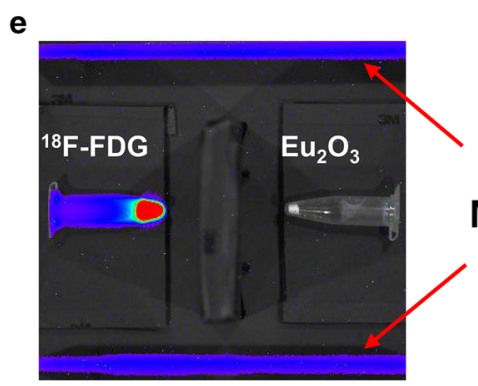

$\mathbf{g}$

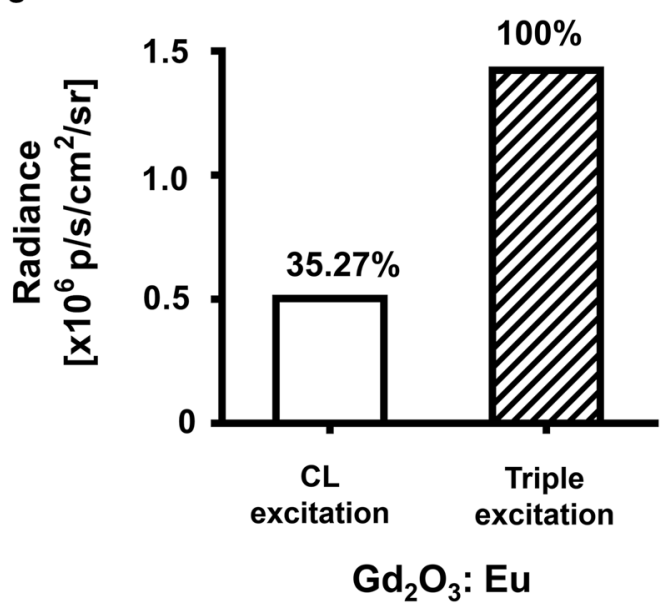

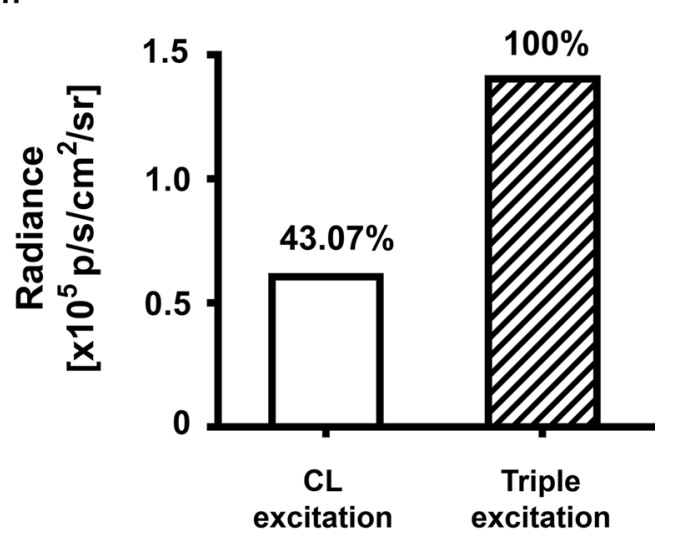

$\mathrm{Eu}_{2} \mathrm{O}_{3}$

Fig. 3 The investigation on the excitation mechanism. $\mathbf{a}$ the overlayed images of the optical signal generated by $\mathrm{Gd}_{2} \mathrm{O}_{3}$ :Eu-100. $\mathbf{b}$ the optical signal intensity of each tube. $\mathbf{c}-\mathbf{f}$ the images of the optical signal generated by $\mathrm{Gd}_{2} \mathrm{O}_{3}$ :Eu-100 through interaction with $\mathrm{CL}$, with $\beta$ particles and $\gamma$ radiation blocked by the lead plate and $\mathrm{CL}$ reflected by the mirrors (c), by $\mathrm{Gd}_{2} \mathrm{O}_{3}$ :Eu-100 through interaction with $\mathrm{CL}$, $\beta$ particles, and $\gamma$ radiation $(\mathbf{d})$, by Eu $\mathrm{O}_{3}$ through interaction with $\mathrm{CL}(\mathbf{e})$ and by $\mathrm{Eu}_{2} \mathrm{O}_{3}$ through interaction with $\mathrm{CL}, \beta$ particles, and $\gamma$ radiation $(\mathbf{f}) . \mathbf{g}$, $\mathbf{h}$ the optical signal intensity of each condition for $\mathrm{Gd}_{2} \mathrm{O}_{3}: \mathrm{Eu}-100(\mathbf{g})$ and $\mathrm{Eu}_{2} \mathrm{O}_{3}(\mathbf{h})$ 
intensity of the ${ }^{18} \mathrm{~F}$-FDG and $\mathrm{Gd}_{2} \mathrm{O}_{3}: \mathrm{Eu}$-100@PVA mixture was enhanced twice of the intensity of ${ }^{18} \mathrm{~F}$-FDG alone upon measurement (Fig. 5b, c).

For in vivo imaging, $\mathrm{Gd}_{2} \mathrm{O}_{3}: \mathrm{Eu}-100 @ P V A$ combined with ${ }^{18} \mathrm{~F}$-FDG provided a higher tumor imaging contrast compared with CLI using ${ }^{18} \mathrm{~F}-\mathrm{FDG}$ alone (Fig. $5 \mathrm{~d}$, e). The optical signal of the tumor was not observed using CLI (Fig. 5d). However, with $\mathrm{Gd}_{2} \mathrm{O}_{3}$ :Eu-100@PVA injected together with ${ }^{18} \mathrm{~F}$-FDG, the optical signal of the tumor was visualized with high contrast using TEFI (Fig. 5e). The tumor-to-normal tissue ratio (TNR) of the $\mathrm{Gd}_{2} \mathrm{O}_{3}: \mathrm{Eu}-100 @ P V A$ and ${ }^{18} \mathrm{~F}-\mathrm{FDG}$ was significantly higher than that of CLI $(10.24 \pm 2.24$ vs. $1.87 \pm 0.73$, $P=0.0030$, Fig. 5f).

\section{Triple-excited fluorescence (TEF) image-guided tumor surgery and biodistribution}

For the mice models injected with ${ }^{18} \mathrm{~F}-\mathrm{FDG}$ and $\mathrm{Gd}_{2} \mathrm{O}_{3}$ :Eu-100@PVA, the PET images acquired $1.5 \mathrm{~h}$ after injection showed no obvious tumor signal (Fig. 5g). However, the TEF images showed an obvious tumor signal (Fig. 5h). The tumor was then resected under the guidance of TEF images, with an ex vivo optical image of the tumor demonstrating that the tumor had an enhanced optical signal compared with normal tissue background (Fig. 5i). The ex vivo tumor signal intensity was significantly higher than that of the surrounding normal tissue $(P=0.0031$, Fig. 5j).

The ex vivo optical images of organs or tissue (tumor, heart, liver, spleen, lung, kidney, intestine, brain, muscle, and blood) of mice assigned to TEFI group were acquired (Fig. 5j). The optical signal intensity of the tumor was way much higher than those of other organs, followed by the heart with a faint optical signal. The optical signal of other organs or tissue was extremely weak, indicating an outstanding capability of tumor delineation using this novel technique.

\section{Discussion}

Radical resection is usually difficult to achieve in surgery of malignant tumors, such as breast cancer, glioblastomas, and lung cancer. Therefore, technologies that can assist intraoperative tumor identification are in urgent need. Optical imaging help to identify tumors in real-time during surgery, which leads to high potential for clinical translation. In this study, $\mathrm{Gd}_{2} \mathrm{O}_{3}$ :Eu NPs have been combined with a commonly used clinical radiopharmaceutical ${ }^{18} \mathrm{~F}$-FDG for outstanding imaging performance. For biomedical use, $\mathrm{Gd}_{2} \mathrm{O}_{3}$ :Eu was modified with PVA, and the performance of tumor imaging and imageguided surgery was investigated in small animal models. It is demonstrated on animal models that the mixed ${ }^{18} \mathrm{~F}-\mathrm{FDG}$ and $\mathrm{Gd}_{2} \mathrm{O}_{3}$ :Eu-100@PVA performs much better than CLI in tumor imaging and it can be successfully used in image-guided surgery.

When mixed with ${ }^{18} \mathrm{~F}$-FDG in vitro, the novel $\mathrm{Gd}_{2} \mathrm{O}_{3}$ :Eu-50 NPs achieve a signal intensity 16.19 times higher than that of $\mathrm{Eu}_{2} \mathrm{O}_{3}$, and approximately 369 times higher than that of $\mathrm{CL}$ generated by ${ }^{18} \mathrm{~F}-\mathrm{FDG}$ alone. The enhanced signal intensity caused by $\mathrm{Gd}_{2} \mathrm{O}_{3}$ :Eu NPs enables in vivo tumor imaging with high contrast. It is also demonstrated that the optical signal intensity decreases as the diameter increases for NPs without PVA modification. This may be affected by the amount of the molecule involved as reported before [32].

The $\mathrm{Gd}_{2} \mathrm{O}_{3}$ : Eu NPs have been modified with PVA for improving biocompatibility, which is widely used [33, 34]. With modification, the optical intensity is weakened compared with $\mathrm{Gd}_{2} \mathrm{O}_{3}: \mathrm{Eu}$ without modification. However, to still take the advantage of high biocompatibility, modified $\mathrm{Gd}_{2} \mathrm{O}_{3}$ : Eu was evaluated in the in vivo experiment of tumor imaging and image-guided surgery. $\mathrm{Gd}_{2} \mathrm{O}_{3}$ :Eu-100@PVA with a diameter of 100 nm generates an optical signal with the highest intensity among the three modified $\mathrm{Gd}_{2} \mathrm{O}_{3}$ :Eu NPs with different diameters. In the experiment of measuring the optical spectrum, the emission light of $700 \mathrm{~nm}$ generated by $\mathrm{Gd}_{2} \mathrm{O}_{3}: \mathrm{Eu}-100 @$ PVA is stronger than that of $\mathrm{Gd}_{2} \mathrm{O}_{3}: \mathrm{Eu}-50 @ P V A$ and $\mathrm{Gd}_{2} \mathrm{O}_{3}:$ Eu-200@PVA. This may be caused by the interaction between PVA and the radiopharmaceutical or the emitted light.

The ex vivo experiments have been performed with $\mathrm{Gd}_{2} \mathrm{O}_{3}: \mathrm{Eu}$ first. It is demonstrated that the optical signal generated from interaction with $\mathrm{CL}, \beta$ particles, and $\gamma$ radiation is 33,40 , and $27 \%$, respectively. The experiment using mirror reflection also achieves a similar percentage of interaction with CL. While in the previous study on REFI with $\mathrm{Eu}_{2} \mathrm{O}_{3}$, only $4.6 \%$ of the optical signal is

\footnotetext{
(See figure on next page.)

Fig. 4 The profile of optical imaging of the $\mathrm{Gd}_{2} \mathrm{O}_{3}$ :Eu and ${ }^{18} \mathrm{~F}-\mathrm{FDG}$ mixture. The contents in the Well 1-9 in this figure are listed as follows: Well 1: saline solution. Well 2: ${ }^{18} \mathrm{~F}-\mathrm{FDG}$. Well 3: $\mathrm{Eu}_{2} \mathrm{O}_{3}+{ }^{18} \mathrm{~F}-\mathrm{FDG}$. Well 4: $\mathrm{Gd}_{2} \mathrm{O}_{3}: \mathrm{Eu}-50+{ }^{18} \mathrm{~F}-\mathrm{FDG}$. Well 5: $\mathrm{Gd}_{2} \mathrm{O}_{3}: \mathrm{Eu}-100+{ }^{18} \mathrm{~F}-\mathrm{FDG}$. Well 6: $\mathrm{Gd}_{2} \mathrm{O}_{3}: \mathrm{Eu}-200+{ }^{18} \mathrm{~F}-\mathrm{FDG}$. Well 7: Gd $\mathrm{O}_{3}: \mathrm{Eu}-50 @ P V A+{ }^{18} \mathrm{~F}-\mathrm{FDG}$. Well 8: Gd $\mathrm{O}_{3}: \mathrm{Eu}-100 @ P V A+{ }^{18} \mathrm{~F}-\mathrm{FDG}$. Well 9: Gd $\mathrm{O}_{3}: \mathrm{Eu}-200 @ P V A+{ }^{18} \mathrm{~F}-\mathrm{FDG}$. a optical imaging with an open filter. $\mathbf{b}$ the emission spectrum of contents in each well. $\mathbf{c}$, $\mathbf{d}$ optical image (c), and quantification of the optical signal intensity (d) with $620 \mathrm{~nm}$ filter. e, foptical image (e), and quantification of the optical signal intensity (f) with $700 \mathrm{~nm}$ filter. $\mathbf{g}$, $\mathbf{h}$ optical image (g), and quantification of the optical signal intensity $(\mathbf{h})$ with swine intestine covered on the top
} 

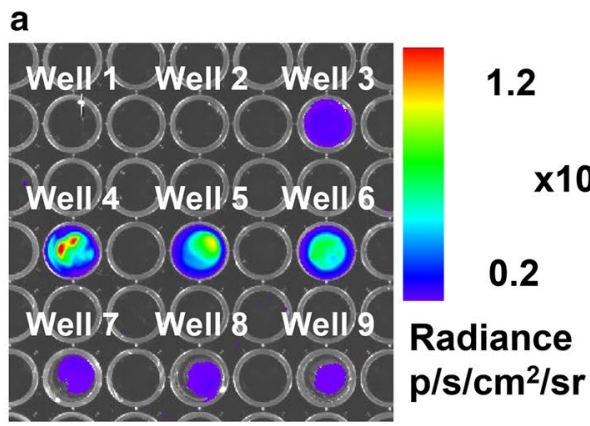

Open filter

c

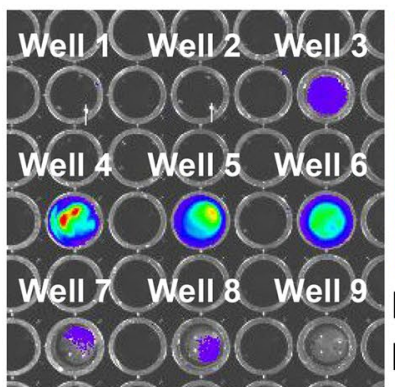

$620 \mathrm{~nm}$ filter

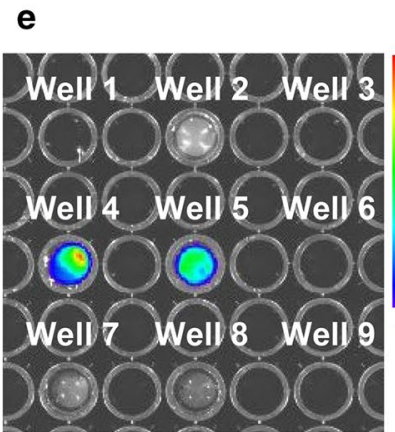

$700 \mathrm{~nm}$ filter
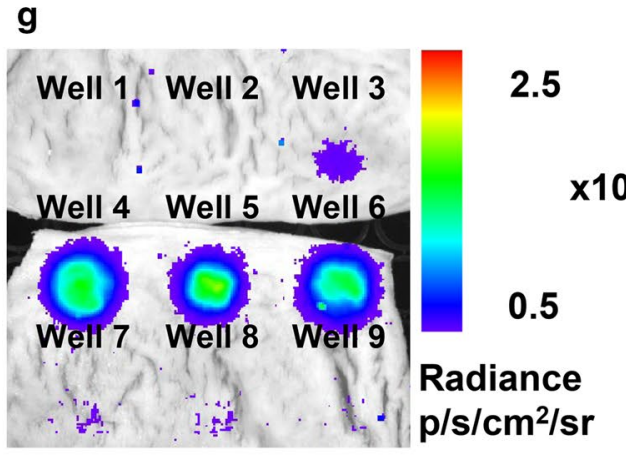

\section{Open filter}

5.0 $\times 10^{8}$

1.0

Radiance $\mathrm{p} / \mathrm{s} / \mathrm{cm}^{2} / \mathrm{sr}$

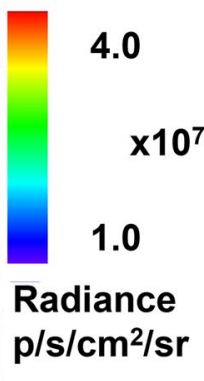

b

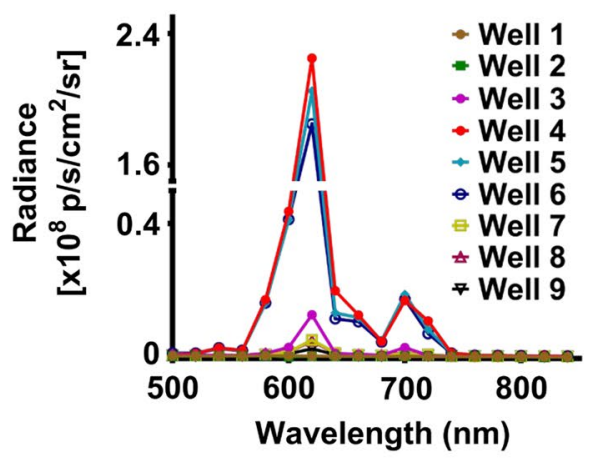

d

f
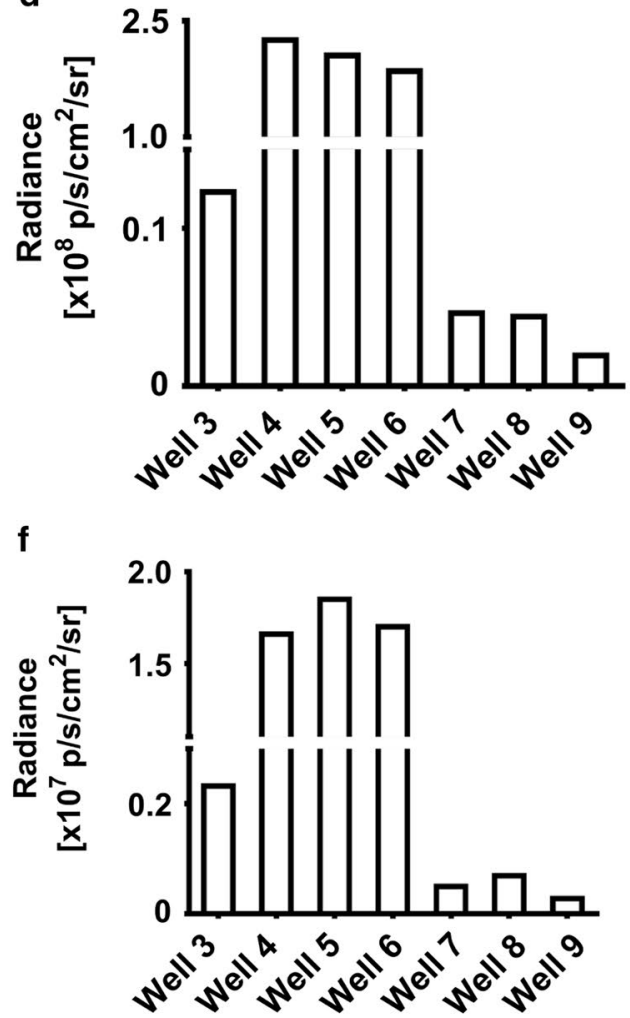

h

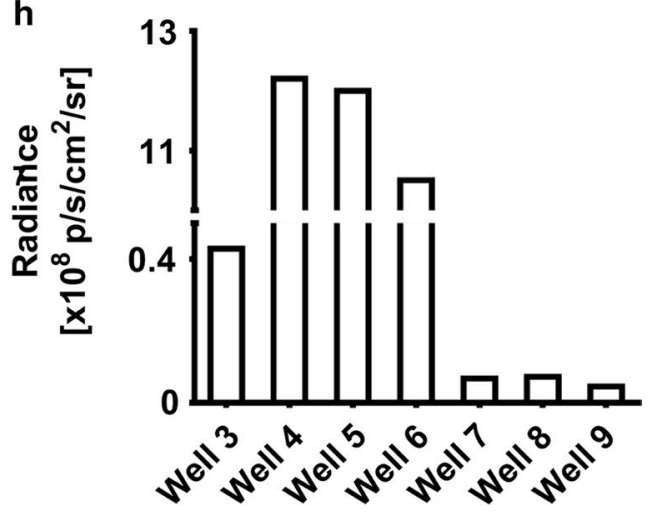



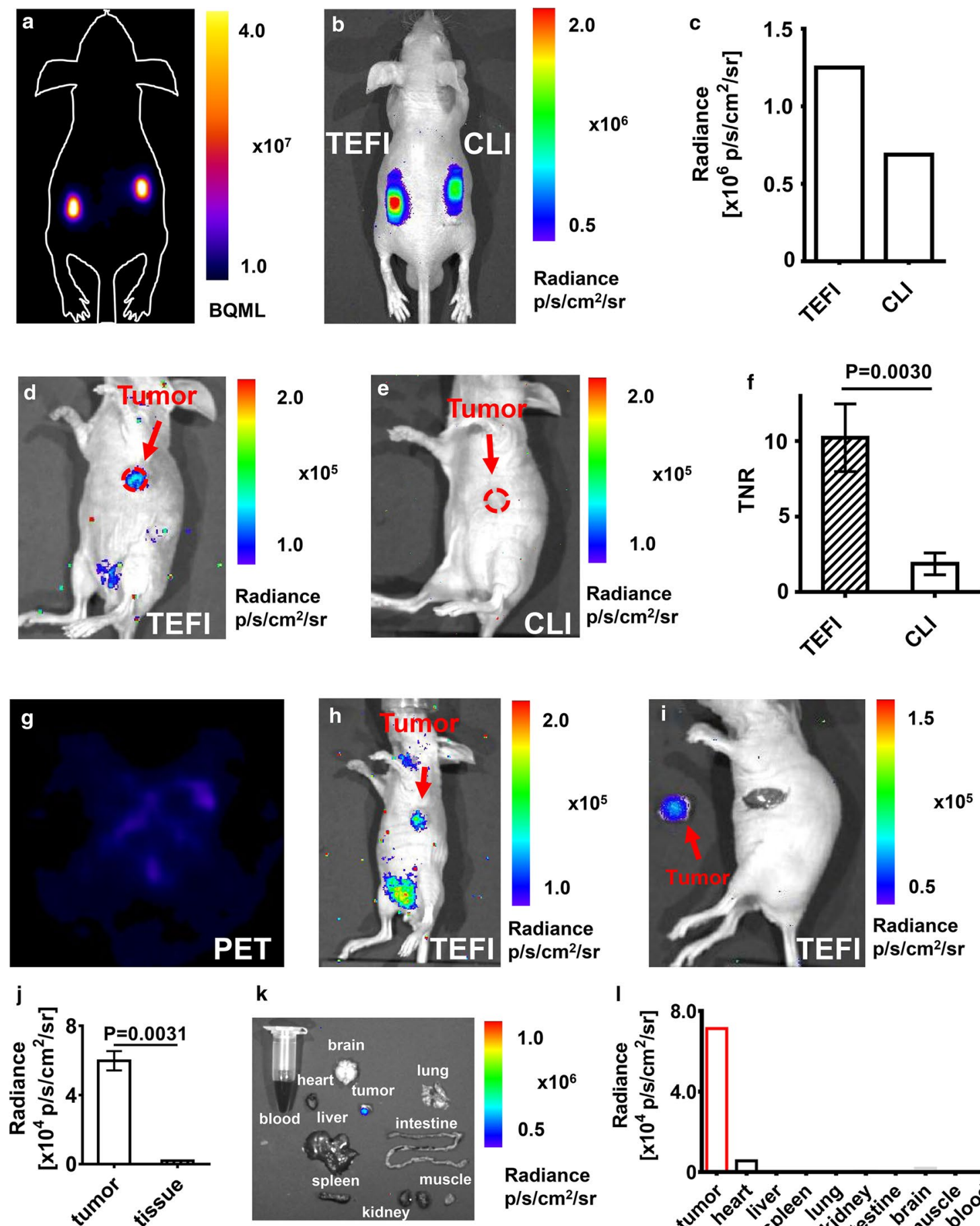

$\mathbf{k}$
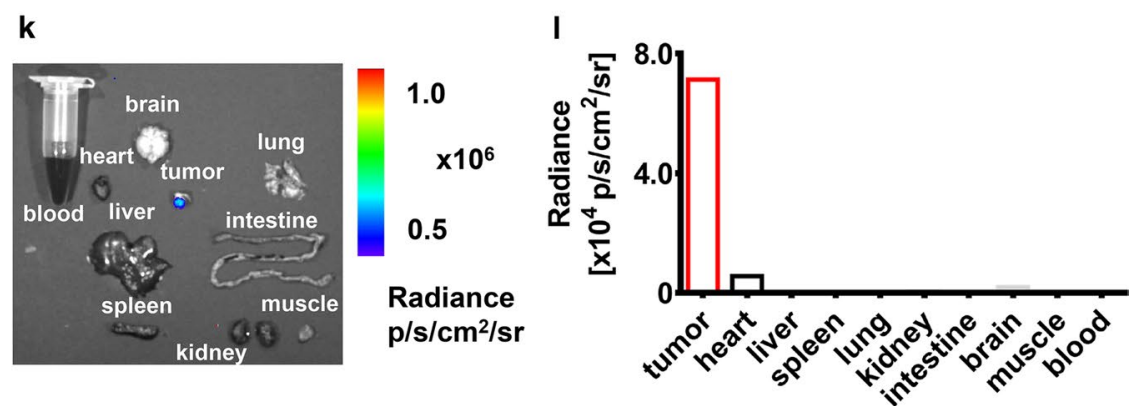

Fig. 5 In vivo phantom and animal experiments. a the PET image of the animal phantom showed the same radioactivity of ${ }^{18} \mathrm{~F}-\mathrm{FDG}$ in the capillaries. $\mathbf{b}$, $\mathbf{c}$ the optical image and the quantitative analysis showed a higher signal intensity of the mixture of $\mathrm{Gd}_{2} \mathrm{O}_{3}: \mathrm{Eu}-100 @ \mathrm{PVA}$ and ${ }^{18} \mathrm{~F}-\mathrm{FDG}$ compared with ${ }^{18} \mathrm{~F}-\mathrm{FDG}$ alone (left: ${ }^{18} \mathrm{~F}-\mathrm{FDG}(84 \mu \mathrm{Ci}, 20 \mu \mathrm{l})+\mathrm{Gd}_{2} \mathrm{O}_{3}$ :Eu@PVA $(2 \mathrm{mg})$, right: $\left.{ }^{18} \mathrm{~F}-\mathrm{FDG}(84 \mu \mathrm{Ci}, 20 \mu \mathrm{l})\right)$. d Gd $\mathrm{O}_{3}$ :Eu-100@PVA enhanced the optical signal of ${ }^{18} \mathrm{~F}-\mathrm{FDG}$, showing an obvious tumor optical signal. e CLI displayed no obvious signal of the tumor. $\mathbf{f}$ the TNR of the tumor was also increased by the $\mathrm{Gd}_{2} \mathrm{O}_{3}$ :Eu-100@PVA NP. $\mathbf{g}$ the PET image of the tumor-bearing mouse injected the mixture of $\mathrm{Gd}_{2} \mathrm{O}_{3}: \mathrm{Eu}-100 @ P V A$ and ${ }^{18} \mathrm{~F}-\mathrm{FDG}$ displayed no obvious tumor signal. $\mathbf{h}$ the $\mathrm{Gd}_{2} \mathrm{O}_{3}$ : Eu 100@PVA enhanced the optical signal of the tumor. $\mathbf{i}$ the tumor was resected with the guidance of the optical image. $\mathbf{j}$ the optical signal intensity of the tumor was significantly higher than that of the surrounding normal tissue. $\mathbf{k}$, I the optical image, and the quantification showed the significantly higher optical signal intensity of tumor compared with muscles and other organs obtained from the tumor-bearing mouse 
generated by $\mathrm{CL}$ and $95.4 \%$ by $\gamma$ radiation [26]. This study indicates that $\mathrm{Gd}_{2} \mathrm{O}_{3}: \mathrm{Eu}$ based nanoparticles are better $\mathrm{CL}$ absorbers than $\mathrm{Eu}_{2} \mathrm{O}_{3}$.

The optical spectrum acquired by optical signal using the IVIS spectrum imaging system aligns with that measured by the spectrometer, with a peak of $620 \mathrm{~nm}$ and a small peak of $700 \mathrm{~nm}$. Compared with CL with a blueultraviolet spectrum, the red-shifted and enhanced light provide deeper penetration and shortened exposure time, which improves the clinical translation potential of TEFI. With the porcine intestine covered on the top of the 96 -well plate containing ${ }^{18} \mathrm{~F}$-FDG and the NPs, the optical signal of the mixture of ${ }^{18} \mathrm{~F}$-FDG and $\mathrm{Gd}_{2} \mathrm{O}_{3}$ : Eu is approximately 28 times higher than that of the ${ }^{18} \mathrm{~F}$-FDG and $\mathrm{Eu}_{2} \mathrm{O}_{3}$ mixture. This demonstrates the improved tissue penetration capacity with $\mathrm{Gd}_{2} \mathrm{O}_{3}$ : Eu combined with ${ }^{18}$ F-FDG. This may enable a reduced dose of NPs used with an outstanding imaging performance, which reduce potential toxicity.

In clinic, PET provides pre-operative imaging on functional and metabolism information of diseases. ${ }^{18} \mathrm{~F}$-FDG used in this study is one of the commonly used radiopharmaceuticals for PET in clinic. In this study, the in vivo PET shows no obvious signal of the tumor. While optical images using $\mathrm{Gd}_{2} \mathrm{O}_{3}$ :Eu-100@PVA and ${ }^{18} \mathrm{~F}$-FDG reveals an obvious optical signal of the tumor. This indicates that the optical imaging of $\mathrm{Gd}_{2} \mathrm{O}_{3}$ :Eu-100@PVA and ${ }^{18} \mathrm{~F}-\mathrm{FDG}$ has high potential for tumor detection.

CLI is an emerging optical imaging method that can use radiopharmaceutical for optical imaging. CLI has been applied in intraoperative imaging in 2017 where ex vivo breast tumor tissue samples are obtained intraoperatively and imaged with a specially designed imaging device for CLI, which is used to display the tumor boundary [9]. However, the optical signal intensity of CLI is relatively weak, restricting the real-time intraoperative tumor imaging. Therefore, various methods have been put forward to achieve the enhancement of optical signal intensity. In 2015, $\mathrm{Eu}_{2} \mathrm{O}_{3} \mathrm{NP}$ was combined with radiopharmaceuticals in optical imaging, demonstrating a better signal-to-background ratio compared with FMI [26]. As the $\mathrm{Eu}_{2} \mathrm{O}_{3}$ NPs mainly interact with $\gamma$ radiation, the enhancement of optical signal intensity obtained by the $\mathrm{Eu}_{2} \mathrm{O}_{3} \mathrm{NP}$ is still needed to be improved. Besides, the NP without surface modification raises the concern of in vivo toxicity. Another imaging technique, Cerenkov radiation energy transfer (CRET), has been explored using clinical radiopharmaceuticals ${ }^{18} \mathrm{~F}$-FDG and ${ }^{18} \mathrm{C}$-choline $\left({ }^{11} \mathrm{C}\right.$-CHO $)$ together with FDA-approved fluorophore fluorescein sodium (FS). The application of FS further improves the potential of clinical translation as it has been approved for clinical use by the FDA and extensively investigated in different imaging fields. However, FS only translates energy of CL into long-wavelength fluorescence, which does not take full advantages of radiation emitted by radiopharmaceuticals except for $\mathrm{CL}$, such as $\beta$ particles and $\gamma$ radiation [18]. In this research, the novel $\mathrm{Eu}^{3+}$ doped gadolinium oxide with PVA modification can translate the energy of $C L, \beta$ particles, and $\gamma$ radiation generated along with the decay process of ${ }^{18} \mathrm{~F}$-FDG. This enhances the optical signal production capability of $\mathrm{Gd}_{2} \mathrm{O}_{3}$ :Eu@PVA NP.

The gadolinium-based nanoparticle was reported to have enhanced MRI T1 signal [35, 36]. Therefore, the nanoparticles reported in this article has the potential to be applied as multi-modality tumor imaging. Besides, as fluorescence imaging with light of longer wavelength has shown outstanding performance [37, 38], novel NPs with emission of longer wavelength are of great potential to combine with radiopharmaceuticals for better biomedical use.

\section{Conclusion}

A novel $\mathrm{Eu}^{3+}$ doped gadolinium oxide $\left(\mathrm{Gd}_{2} \mathrm{O}_{3}: \mathrm{Eu}\right)$ is combined with ${ }^{18} \mathrm{~F}$-FDG to achieve a red-shifted emitting spectrum and enhanced optical signal intensity. The high conversion efficiency of the radiation energy is realized using the novel NP. Moreover, with PVA modification, $\mathrm{Gd}_{2} \mathrm{O}_{3}$ :Eu@PVA with high biocompatibility shows capability for tumor imaging and image-guided surgery in small animal models. Our study highlights that combining $\mathrm{Gd}_{2} \mathrm{O}_{3}$ : Eu with ${ }^{18} \mathrm{~F}$-FDG greatly integrate the merit of optical imaging and nuclear imaging, worthy of further investigation of more NPs with improved optical properties and biocompatibility for pre-clinical and clinical use.

\section{Supplementary Information}

The online version contains supplementary material available at https://doi. org/10.1186/s12951-021-00920-6.

Additional file 1: Figure 1. The optical images with different interaction distances and radioactivity.

\section{Acknowledgements}

We thank Prof. Zhanjun Gu and Dr. Linji Gong from the Institute of High Energy Physics Chinese Academy of Sciences for the technical assistance on the preparation of the nanoparticles involved in this manuscript.

\section{Authors' contributions}

XS performed the experiment, analyzed the data acquired and wrote the manuscript. ZH and JT supervised the designation of the experiments. CC and ZZ assisted with data analysis.

\section{Funding}

This study was supported by the National Key Research and Development Program of China (2017YFA0205200), National Natural Science Foundation of China (NSFC) $(62027901,81930053,92059207,81227901)$, Beijing Natural Science Foundation (JQ19027), the innovative research team of high-level local universities in Shanghai, and the Zhuhai High-level Health Personnel Team 
Project (Zhuhai HLHPTP201703). The authors would like to acknowledge the instrumental and technical support of the multi-modal biomedical imaging experimental platform, Institute of Automation, Chinese Academy of Sciences.

\section{Availability of data and materials}

The data generated or analyzed during this study are included in the manuscript and the supplementary information files.

\section{Declarations}

\section{Ethics approval and consent to participate}

This study only involved small animals. All the experimental procedures involving animals were approved by the Institutional Animal Care and Use Committee of the Fifth Affiliated Hospital, Sun Yat-sen University (2020071401).

\section{Consent for publication}

All the co-authors have approved the manuscript and agree with submission to your esteemed journal. No individual person's data was involved in this manuscript.

\section{Competing interests}

The authors declare that they have no competing interests.

\section{Author details}

${ }^{1}$ CAS Key Laboratory of Molecular Imaging, Beijing Key Laboratory of Molecular Imaging, The State Key Laboratory of Management and Control for Complex Systems, Institute of Automation, Chinese Academy of Sciences, Beijing, China. ${ }^{2}$ School of Artificial Intelligence, University of Chinese Academy of Sciences, Beijing, China. ${ }^{3}$ Beijing Advanced Innovation Center for Big Data-Based Precision Medicine, School of Medicine, Beihang University, Beijing, China.

Received: 9 April 2021 Accepted: 31 May 2021

Published online: 16 July 2021

\section{References}

1. Mitchell GS, Gill RK, Boucher DL, Li C, Cherry SR. In vivo Cerenkov luminescence imaging: a new tool for molecular imaging. Philos TR Soc A. 1955;2011(369):4605-19.

2. Grootendorst MR, Cariati M, Kothari A, Tuch DS, Purushotham A. Cerenkov luminescence imaging (CLI) for image-guided cancer surgery. Clin Transl Imaging. 2016;4(5):353-66.

3. Zhang Z, Cai M, Bao C, Hu Z, Tian J. Endoscopic Cerenkov luminescence imaging and image-guided tumor resection on hepatocellular carcinoma-bearing mouse models. Nanomed-Nanotechnol. 2019;17:62-70.

4. Qin C, Zhong J, Hu Z, Yang X, Tian J. Recent advances in Cerenkov luminescence and tomography imaging. IEEE J Sel Top Quant. 2011;18(3):1084-93.

5. Robertson R, Germanos MS, Li C, Mitchell GS, Cherry SR, Silva MD. Optical imaging of Cerenkov light generation from positron-emitting radiotracers. Phys Med Biol. 2009;54(16):N355

6. Zhang Z, Qu Y, Cao Y, Shi X, Guo H, Zhang X, Zheng S, Liu H, Hu Z, Tian J. A novel in vivo Cerenkov luminescence image-guided surgery on primary and metastatic colorectal cancer. J Biophotonics. 2020;13(3):e201960152.

7. Song T, Liu X, Qu Y, Liu H, Bao C, Leng C, Hu Z, Wang K, Tian J. A novel endoscopic Cerenkov luminescence imaging system for intraoperative surgical navigation. Mol Imaging. 2015;14(8):7290.2015.00018.

8. Liu M, Zheng S, Zhang X, Guo H, Shi X, Kang X, Qu Y, Hu Z, Tian J. Cerenkov luminescence imaging on evaluation of early response to chemotherapy of drug-resistant gastric cancer. Nanomed-Nanotechnol. 2018;14(1):205-13.

9. Grootendorst MR, Cariati M, Pinder SE, Kothari A, Douek M, Kovacs T, Hamed H, Pawa A, Nimmo F, Owen J, Ramalingam V, Sethi S, Mistry S, Vyas K, Tuch DS, Britten A, Hemelrijck MV, Cook GJ, Sibley-Allen C, Allen S, Purushotham A. Intraoperative assessment of tumor resection margins in breast-conserving surgery using 18F-FDG Cerenkov luminescence imaging: a first-in-human feasibility study. J Nucl Med. 2017;58(6):891-8.
10. Spinelli AE, Ferdeghini M, Cavedon C, Zivelonghi E, Calandrino R, Fenzi A, Sbarbati A, Boschi F. First human cerenkography. J Biomed Opt. 2013;18(2):020502.

11. Liu H, Ren G, Liu S, Zhang X, Chen L, Han P, Cheng Z. Optical imaging of reporter gene expression using a positron-emission-tomography probe. J Biomed Opt. 2010;15(6):060505.

12. Liu H, Carpenter CM, Jiang H, Pratx G, Sun C, Buchin MP, Gambhir SS, Xing L, Cheng Z. Intraoperative imaging of tumors using Cerenkov luminescence endoscopy: a feasibility experimental study. J Nucl Med. 2012;53(10):1579-84.

13. Xu Y, Chang E, Liu H, Jiang H, Gambhir SS, Cheng Z. Proof-of-concept study of monitoring cancer drug therapy with Cerenkov luminescence imaging. J Nucl Med. 2012;53(2):312-7.

14. Liu H, Ren G, Miao Z, Zhang X, Tang X, Han P, Gambhir SS, Cheng Z. Molecular optical imaging with radioactive probes. PLOS ONE. 2010;5(3):e9470.

15. Lee SB, Yoon GS, Lee SW, Jeong SY, Ahn BC, Lim DK, Lee J, Jeon YH. Combined positron emission tomography and Cerenkov luminescence imaging of sentinel lymph nodes using PEGylated radionuclide-embedded gold nanoparticles. Small. 2016;12(35):4894-901.

16. Lee SB, Kumar D, Li Y, Lee IK, Cho SJ, Kim SK, Lee SW, Jeong SY, Lee J, Jeon YH. PEGylated crushed gold shell-radiolabeled core nanoballs for in vivo tumor imaging with dual positron emission tomography and Cerenkov luminescent imaging. J Nanobiotechnol. 2018;16(1):1-12.

17. Liu H, Zhang X, Xing B, Han P, Gambhir SS, Cheng Z. Radiation-luminescence-excited quantum dots for in vivo multiplexed optical imaging. Small. 2010;6(10):1087-91.

18. Thorek DL, Ogirala A, Beattie BJ, Grimm J. Quantitative imaging of disease signatures through radioactive decay signal conversion. Nat Med. 2013;19(10):1345.

19. Zheng S, Zhang Z, Qu Y, Zhang X, Guo H, Shi X, Cai M, Cao C, Hu Z, Liu H, Tian J. Radiopharmaceuticals and fluorescein sodium mediated triplemodality molecular imaging allows precise image-guided tumor surgery. Adv Sci. 2019;6(13):1900159.

20. Glaser AK, Zhang R, Andreozzi JM, Gladstone DJ, Pogue BW. Cherenkov radiation fluence estimates in tissue for molecular imaging and therapy applications. Phys Med Biol. 2015;60(17):6701.

21. Shaffer TM, Drain CM, Grimm J. Optical imaging of ionizing radiation from clinical sources. J Nucl Med. 2016;57(11):1661-6.

22. Ha SW, Cho HS, Yoon YI, Jang MS, Hong KS, Hui E, Lee JH, Yoon TJ. Ions doped melanin nanoparticle as a multiple imaging agent. J Nanobiotechnol. 2017;15(1):1-9.

23. Liu C, Li Z, Hajagos TJ, Kishpaugh D, Chen DY, Pei Q. Transparent ultrahigh-loading quantum dot/polymer nanocomposite monolith for gamma scintillation. ACS Nano. 2017;11(6):6422-30.

24. Cao X, Chen X, Kang F, Zhan Y, Cao X, Wang J, Liang J, Tian J. Intensity enhanced Cerenkov luminescence imaging using terbium-doped $\mathrm{Gd}_{2} \mathrm{O}_{2} \mathrm{~S}$ microparticles. ACS Appl Mater Inter. 2015;7(22):11775-82.

25. Ma X, Kang F, Xu F, Fang A, Zhao Y, Lu T, Yang W, Wang Z, Lin M, Wang J. Enhancement of Cerenkov luminescence imaging by dual excitation of $\mathrm{Er}^{3+}, \mathrm{Yb}^{3+}$-doped rare-earth microparticles. PLoS ONE. 2013;8(10):e77926.

26. Hu Z, Qu Y, Wang K, Zhang X, Zha J, Song T, Bao C, Liu H, Wang Z, Wang J, Liu Z, Liu H, Tian J. In vivo nanoparticle-mediated radiopharmaceuticalexcited fluorescence molecular imaging. Nat Commun. 2015;6(1):1-12.

27. Hu Z, Zhao M, Qu Y, Zhang X, Zhang M, Liu M, Guo H, Zhang Z, Wang J, Yang W, Tian J. In vivo 3-dimensional radiopharmaceutical-excited fluorescence tomography. J Nucl Med. 2017;58(1):169-74.

28. Hu Z, Chi C, Liu M, Guo H, Zhang Z, Zeng C, Ye J, Wang J, Tian J, Yang W, Xu W. Nanoparticle-mediated radiopharmaceutical-excited fluorescence molecular imaging allows precise image-guided tumor-removal surgery. Nanomed-Nanotechnol. 2017;13(4):1323-31.

29. Liu N, Shi J, Wang Q, Guo J, Hou Z, Su X, Zhang H, Sun X. In vivo repeatedly activated persistent luminescence nanoparticles by radiopharmaceuticals for long-lasting tumor optical imaging. Small. 2020;16(26):2001494.

30. Liu N, Chen $X$, Sun $X$, Sun $X$, Shi J. Persistent luminescence nanoparticles for cancer theranostics application. J Nanobiotechnol. 2021;19(1):1-24. 
31. Zhou L, Gu Z, Liu X, Yin W, Tian G, Yan L, Jin S, Ren W, Xing G, Li W, Chang $X, \mathrm{Hu} Z$, Zhao Y. Size-tunable synthesis of lanthanide-doped Gd 203 nanoparticles and their applications for optical and magnetic resonance imaging. J Mater Chem. 2012;22(3):966-74.

32. Pratt EC, Shaffer TM, Zhang Q, Drain CM, Grimm J. Nanoparticles as multimodal photon transducers of ionizing radiation. Nat Nanotechnol. 2018;13(5):418-26.

33. Alexandre N, Ribeiro J, Gärtner A, Pereira T, Amorim I, Fragoso J, Lopes A Fernandes J, Costa E, Silva AS, Rodrigues M, Santos JD, Maurício AC, Luis AL. Biocompatibility and hemocompatibility of polyvinyl alcohol hydrogel used for vascular grafting-In vitro and in vivo studies. J Biomed Mater Res A. 2014;102(12):4262-75.

34. Hamdalla TA, Hanafy TA. Optical properties studies for PVA/Gd, La, Er or Y chlorides based on structural modification. Optik. 2016;127(2):878-82.

35. Yin J, Wang $X$, Zheng H, Zhang J, Qu H, Tian L, Zhao F, Shao Y. Silica nanoparticles decorated with gadolinium oxide nanoparticles for magnetic resonance and optical imaging of tumors. ACS Appl Nano Mater. 2021;4(4):3767-79.
36. Han C, Xie T, Wang K, Jin S, Li K, Dou P, Yu N, Xu K. Development of fluorescence/MR dual-modal manganese-nitrogen-doped carbon nanosheets as an efficient contrast agent for targeted ovarian carcinoma imaging. J Nanobiotechnol. 2020;18(1):1-15.

37. Hu Z, Chen W, Tian J, Cheng Z. NIRF nanoprobes for cancer molecular imaging: approaching clinic. Trends Mol Med. 2020;26(5):469-82.

38. Hu Z, Fang C, Li B, Zhang Z, Cao C, Cai C, Su S, Sun X, Shi X, Li C, Zhou T, Zhang Y, Chi C, He P, Xia X, Chen Y, Gambhir SS, Cheng Z, Tian J. Firstin-human liver tumour surgery guided by multispectral fluorescence imaging in the visible and near-infrared-1//l windows. Nat Biomed Eng. 2020;4(3):259-71.

\section{Publisher's Note}

Springer Nature remains neutral with regard to jurisdictional claims in published maps and institutional affiliations.
Ready to submit your research? Choose BMC and benefit from:

- fast, convenient online submission

- thorough peer review by experienced researchers in your field

- rapid publication on acceptance

- support for research data, including large and complex data types

- gold Open Access which fosters wider collaboration and increased citations

- maximum visibility for your research: over $100 \mathrm{M}$ website views per year

At BMC, research is always in progress.

Learn more biomedcentral.com/submissions 